\title{
Pre-trade trasparency on the Italian Stock Exchange: a trade size model on panel data*
}

\author{
Caterina Lucarelli ${ }^{\dagger}$ \\ Maria Elena Bontempi $i^{\ddagger}$ \\ Camilla Mazzoli ${ }^{\S}$ \\ Anna Grazia Quaranta
}

\begin{abstract}
The purpose of this study was to analyze the effects that have been caused by changes in pre-trade transparency upon the behavior of stock traders. We used a trade size model and tested it before, during and after the period when the Italian Stock Exchange introduced a 20-level order book with disaggregated orders. Tick by tick data of the whole set of stocks (up to 277) listed on the Italian Stock Exchange were studied through fixed-effects panel models, within intra day (every 30 minutes and 150 minutes) and daily time frames. Our results indicate that order flows, bidask spreads, levels of risk and some information events differentially affect trade sizes when investors receive better information prior to negotiation. Both (intra day) informed and uninformed traders operating in a more transparent market became more reticent, with reduced trades sizes and higher orders' cancellations. Moreover, it appears that the higher degree of order book disclosure permits traders to downsize their level of risk aversion; i.e. it reduces the 'uncertainty' that would otherwise result in disrupted trading activity under conditions of information opacity.
\end{abstract}

JEL Classification: G14; D03; D82; C23; C82.

Key words: pre-trade transparency; trade size; private information; panel data.

\footnotetext{
*We are grateful to Investnet-IW Bank for providing us with the trading platform used to download the data set. We would like also to thank Roberto Golinelli for his useful comments and advice; Massimiliano Ghedini, Ivan Girotto and CINECA for providing a powerful HPC computer to deal the huge dimension of the dataset.

${ }^{\dagger}$ Corresponding author, Università Politecnica delle Marche, Department of Economics, Piazzale Martelli 8, I-60121, Italy, tel. +39 071 2207196, fax: +39 071 2207253, c.lucarelli@univpm.it.

${ }^{\ddagger}$ Università degli Studi di Bologna, mariaelena.bontempi@unibo.it.

$\S$ Università Politecnica delle Marche, c.mazzoli@univpm.it.

ฯUniversità degli Studi di Bologna, annagrazia.quaranta@unbo.it.
} 


\section{Introduction}

The way in which private information is impounded in the trading process forms an important aspect of studies into security market microstructures (O'Hara, 1995; Madhavan, 2000; Hasbrouck, 2007). The pre-trade transparency (PTT), inherent to electronic order books, permits the dynamic visibility of prices, quotes and volumes, and increases the level of disclosure in the trading process. As a consequence, it can be argued that when PTT is enhanced, the trading process becomes more informative and the number of market participants able to interpret the trading behavior of informed traders is increased. Furthermore, the higher the level of PTT, the greater the extent that private information held by informed traders can be shared (indirectly, via the trading process) with all the market participants. It is upon this basis that it has been often stated that informed traders resist transparency, while liquidity/noise traders welcome it (among the others Madhavan, 2000).

Since the beginning of electronic trading, the Italian Stock Exchange's (ISE) pretrade transparency standards have been largely asymmetric between institutional (mainly banks) and retail traders. Whilst institutional traders have had access to transparent order books (unanonymous with disaggregated orders throughout), retail traders have only had access to 5-level anonymous order books containing aggregated orders. The purpose of this study was to reveal how changes in PTT can affect trading behavior. We focused on the effects that an innovative trading device has had upon the market microstructure. The trading device, called 'Book Profondo' (BP), was introduced to the ISE between $1^{\text {st }}$ and $31^{\text {st }}$ July 2007 ; it was based on a 20 -level order book with disaggregated orders and was distributed to all of the market's participants. Even if the asymmetry in anonymity has remained the same, the introduction of the BP represents a relevant improvement in PTT since informed traders are forced to manage the exposure of their orders when facing higher transparency (Bohemer et al., 2005; Harris, 1996). The segment of the market affected by BP is the 'Mercato Telematico Azionario' (MTA) - the ISE traditional equity market. This segment is an electronic order driven market where negotiations are based on a limit order book. The BP innovation increased the amount of information made available during the trading process in terms of enhanced visibility of order flow dynamics, especially in the favor of retail traders. Assuming a higher probability that institutional traders exercise informationbased trading (Simaan et al., 2003), we can argue that the BP would have changed the proportion of traders that are able to share private information. This would happen because a larger number of market participants (retail traders) are allowed to tread in the footsteps of informed traders (institutional traders) ${ }^{1}$. Thus, this study considers the behavior of both institutional and retail investors, who have respectively lost and

\footnotetext{
${ }^{1}$ In Italy, a high level of PTT asymmetry exists between market participants. It is not reasonable that informed, but non-institutional, traders are able to exploit private information using an opaque order book, whilst knowing that their orders are visible to institutional investors. In fact, before the release of BP, some big (informed) retail traders used to trade through the fully transparent platforms of institutional traders (whose names are to be considered confidential, because this procedure was contralegem). Thus, in the present study, we have assumed that informed traders always take advantage (either directly or indirectly) of the degree of PTT that is disclosed to institutional investors.
} 
gained advantages following the introduction of BP.

Our models assume that trade sizes reflect the choices of traders formed on the basis of the information they obtain (Chan, 2000; Simaan et al., 2003; Lin et al., 1995). As a consequence, we have tested trade size models under different conditions of market transparency.

The study addressed different time frames: a very short, intra day time frame (the 30 minute analysis), a medium-short intra day time frame (the 150 minute analysis) and a daily time frame. The rationale was to capture the behavior of all traders, whatever their time-horizon, even though the PTT devices are known to be mainly exploited by short-term traders (the so called 'scalpers' or 'momentum' traders). It was therefore expected that the intra day models would best demonstrate the effect of enhanced PTT.

We have considered tick by tick data on the whole set of stocks listed on the ISE and traded on the MTA equity market, for a maximum of 277 shares, over a six months period running between $15^{\text {th }}$ May 2007 and $15^{t h}$ November 2007. This period was divided into three sub-periods, in accordance with the methodology already used by Bohemer et al. (2005):

1. from $15^{\text {th }}$ May 2007 to $30^{\text {th }}$ June 2007: prior to the introduction of BP and characterized by the lowest level of pre-trade transparency (Book 1 or B1);

2. from $1^{\text {st }}$ July 2007 to $30^{\text {th }}$ August 2007: during the introduction of BP and characterized by an improvement in the level of pre-trade transparency (Book 2 or B2);

3. finally, from $1^{\text {st }}$ September 2007 to $15^{\text {th }}$ November 2007: following the introduction of BP and with the highest level of pre-trade transparency ever experienced by ISE (Book 3 or B3).

Fixed-effects panel models were tested over the aforementioned time frames, being either intra day (30 minute and 150 minute) or daily analyses. The estimates were run separately for the three sub-periods (B1, B2 and B3) in order to capture how a set of explanatory variables can differentially affect choices made on trade size when investors receive better information prior to trading. For each sub-period and time frame, different models were run to test various indicators of order flows (order intensity or a set of inter quote durations), levels of risk (the Garman and Klass (1980) indicator or the degree of statistical volatility) and, finally, of the disclosure of information events (time series, such as future/spot interest rates or information dummies). The results of these analyses also contributed therefore to identifying the choice of variables that best fit the models for each of the different time frames observed.

Moreover, our methodology adds toutcourt information to the wealth of data on market microstructures. In fact, a very few studies published up to now within this field have used panel data based on tick by tick data as we have done. The panel model permits a full explanation of cross-individual heterogeneity and of time-dimension variability. This introduces a third dimension of analysis compared to the single stock and market wide perspectives (see for all Lo and Wang, 2001). 
Regarding the intra day time frames, the results prove our models to be statistically informative, especially when pre-trade transparency is at its best, whilst on the daily time frame models weaken as far as both reliability and clearness of results As a general result, we found that order flows, bid-ask spreads, levels of risk and some information events differentially affect trade sizes when all the investors have access to better information prior to negotiation. The introduction of BP induced traders becoming more cautious, as far the disclosure of their trading choices is concerned, and less averse to risk.

In the following sections of this paper, section 2 reviews the main contributions available in literature regarding pre-trade transparency; section 3 describes the main clearing and filtering rules applied to manage the tick by tick data set and to fit it to the panel framework; section 4 describes the variables and the models, and section 5 summarises the main findings obtained; section 6 presents the conclusions of this study and outlines the future lines of research required to deepen our understanding of the effects of PTT.

\section{Literature Review}

Pre-trade transparency refers to the entitlement of market participants to observe the pending trading interests of others; or, in other words, the exposure of the limit order books' contents (Bohemer, Saar and Yu, 2005). It is often cited in literature that the level of PTT is able to influence the trading behaviour. Previous studies on this topic have mainly focused on the information disclosed to investors in quote driven markets. As a consequence, such studies have addressed whether a change in the PTT is able to influence the behaviour of liquidity providers who play a crucial role in quote driven markets. The main assumption of these studies is that a higher level of transparency (very often associated with the removal of anonymity) allows market makers to discriminate between informed traders and uninformed traders; as a consequence, the cost of trading decreases in terms of the bid-ask spread in accordance with the inventory and with the adverse selection paradigms (Stoll, 1976, 1978; Amihud and Mendelson, 1980). Chowdhry and Nanda (1991) and Forster and George (1992) have both proposed models where a higher level of transparency is provided in order to attract more uninformed traders and discourage insider trading; in these models, market makers charge lower bid-ask spreads because they face lower adverse selection costs. Harris and Schultz (1997) found that market makers fix wider bid-ask spreads when they trade on the anonymous Small Order Execution System (SOES) of the Nasdaq compared to when they trade on the non-anonymous dealer market. Theissen (2003) found similar results for the Frankfurt Stock Exchange showing that when market makers trade on the non-anonymous, floor-based trading system, they can identify uninformed traders and consequently bear less risk. Huang and Stoll (1996) have compared two markets: the NYSE, where market makers can see the limit order book, and the Nasdaq, where they cannot; they found that spreads were generally higher on the Nasdaq.

Nowadays, a large number of stock exchanges worldwide are characterised by order driven markets (or hybrid markets), rather than by quote driven markets. Focault, Moinas and Theissen (2007) analyzed the changes in the Euronext limit order mar- 
ket after its transition to an anonymous order book on $23^{\text {rd }}$ April 2001. They found evidence that after this transition the bid-ask spread significantly decreased. They maintain that the information content of the order book reduces when trading is anonymous. Informed traders react by posting aggressive offers more frequently when their identities are hidden. Bohemer, Saar and Yu (2005) investigated the consequences of increased levels of pre-trade transparency in the NYSE stock exchange upon the trading strategies of both traders and liquidity providers. They found that informed traders react to an increase in the level of transparency by trading more actively; they tend to break up their orders, submitting limited orders of smaller sizes, and they increase cancellation rates in order to avoid any front running of their orders by others.

In contrast with the previous literature, we have developed a trade size model instead of a bid-ask spread model. Many authors use bid-ask spread models to analyze the effects of a change in the anonymity of the order book. In this case, the ISE's PTT anonymity standards were not affected by the introduction of the BP: institutional traders still rely on a non-anonymous order book, while retail traders deal with an anonymous one. Moreover, our main interest is related to the behaviour of traders in relation to the information they hold; assuming that trading at large volume is more likely to be associated with informed trading (Chan, 2000; Simaan et al., 2003; Lin et al., 1995), a trade size model seems to be more appropriate.

\section{The database management}

The whole data set is stored in a data warehouse and configured according to the following structure:

Table 1: The original data set layout

\begin{tabular}{lcccrc}
\hline Stock $_{j}$ & Day $_{j}$ & Time $_{t}$ & $\mathrm{P}_{i t}$ & $\mathrm{~V}_{i t}$ & $\mathrm{TT}_{i t}$ \\
\hline PG.MIL & $15 / 05 / 2007$ & 9.03 .01 & 0.462 & 4414019 & 0 \\
PG.MIL & $15 / 05 / 2007$ & 9.05 .05 & 0.462 & 114256 & 0 \\
PG.MIL & $15 / 05 / 2007$ & 9.05 .05 & 0.462 & 2204 & 0 \\
PG.MIL & $15 / 05 / 2007$ & 9.05 .10 & 0.474 & 32700 & 2 \\
PG.MIL & $15 / 05 / 2007$ & 9.05 .13 & 0.460 & 23150 & 1 \\
PG.MIL & $15 / 05 / 2007$ & 9.05 .27 & 0.475 & 12500 & 2 \\
\hline
\end{tabular}

$P_{i t}$ and $V_{i t}$ are the price and volume associated either to a trade or to an order (bid or ask) that refer to stock $i$ at time $t . T T_{i t}$ indicates whether the operation is a trade or an order: $T T_{i t}=0$ is for a trade; $T T_{i t}=1$ is for a bid order; $T T_{i t}=2$ is for an ask order.

We used the following filtering rules in order to clean the data set and produce a tick by tick structure coherent with a panel framework:

1. data gaps or server errors were excluded when price $\left(P_{i t}\right)$ or volume $\left(V_{i t}\right)$ were equal to 0 ; 
2. the overall data set, based on a tick by tick framework, could have repeated observations of trade/quote prices and volumes across data points, for each second. Table 2 and Table 3 in Appendix 1 describe typical repeated observations and the rules we followed to manage them.

3. observations were limited to when the stock exchange was open, excluding the first and the last hour of negotiations in order to omit deals that might have been influenced by market makers' inventory strategies. Thus, transactions performed outside the period 9.31.00AM-5.00.59PM were discarded.

4. extreme outliers that characterized relative-bid-ask spread, levels of risk and order imbalance indicators were also dropped (see section 4). A total of seven stocks were eliminated whose time-dimensions were not adequately long enough for our analysis.

The data management and cleaning procedures, the identification of the variables, the exploratory data analysis and empirical estimates were all carried out using the Stata/MP 10 Parallel Edition for Linux64 and a powerful HPC computer (IBM-BCX) that was kindly made available to academic users by CINECA (at the Italian Ministry of Research). IBM-BCX is a cluster of 2560 dual-core AMD opteron processors (5120 cores in total) dedicated to massive parallel applications and special High-End projects. Following the initial cleaning procedures, the tick by tick data sets of bid and ask quotes (in Stata format) each reached 2 gigabytes in file dimensions (more than 50 million panel observations, 277 stocks with an average of about 181,000 temporal observations); the data set of trades became a (in Stata format) 0.5 gigabyte file (more than 10 millions observations, 277 stocks with an average of about 38,000 temporal observations).

\section{The model}

We developed a trade size model and tested under different conditions of market transparency, according to the methodology already used by Bohemer et al. (2005) (see section 1). Dynamics are important in our model due to the persistent nature of trading behavior. For example, if a share is traded according to a specific trade size in the period t-1, it may also be reasonably traded with a similar size in the period t. A significant change in the trade size may be interpreted by the market participants as a signal of private information; that is why such activity is prudently avoided by informed traders, especially when the market is transparent. Moreover, traders are used to being attracted to 'glittering' or 'commonly-used' stocks (Barber and Odean, 2008) that intensify the persistence of trades. Our model also aims to identify the other factors that affect stock trade sizes: order flows, transaction costs (the relative bid-ask spread), levels of risk of stocks, the contingent situation of the market (order imbalance) and the disclosure of information events. The greater the intensity of the order flows, the more 'emotional' the trading process becomes; in turn, this may spread about a sort of 'trading pressure' among the market participants and affect their trade sizes. The lower the (fixed) transaction cost of a share, the more liquid it becomes, thus inducing traders to deal larger trade sizes, as already proposed by Brennan and Subrahmanyam 
(1998). Moreover, the more liquid a stock is (with a low bid-ask spread), the more comfortable a trader will feel with higher trade sizes. This is to say that more liquid stocks attract informed traders willing to deal with larger trade sizes. By incorporating risk measures into our model we aim to shed light on the well known debate of volumevolatility interconnections. In general, results on the US markets, especially on the daily time frame, have revealed a positive link (Brennan and Subrahmanyam, 1998). Here we look for signs of such a relationship, whilst referring to a different stock exchange (the ISE) and over different time frames. The variable 'order imbalance' might also be able to capture the contingent situation of the market; more precisely, whether it is bearish (with considerable selling pressure) or bullish (considerable bid pressure). In the study of a US market, the order imbalance generally positively affects trading volumes (Chordia et al., 2001).

Finally, our model was applied across three different time frames: 30 minutes, 150 minutes (intra day time frames) and daily. The main reasons to run this experiment were:

- to identify differences between traders' behaviors (whatever their time-horizon specialization) and to compare the results between the intra day and daily time frame. We expected that a change in the PTT would be more significant within the intra day perspectives;

- to test (across the different time frames) the various indicators of order flows (the order intensity or a set of inter quote durations) and risk (the Garman-Klass indicator or the statistical volatility) and assess the effects of the disclosure of information events (information time series such as future/spot interest rates, or news dummies);

- to manage the trade-off between running a very short term analysis and the need to avoid the micro-structure noise that has been proved to bias high frequency data (Hansen and Lunde, 2006; Bandi and Russell, 2006).

\subsection{The variables}

Our empirical model is based on the variables listed below. Variable $i$ represents the stocks investigated, where $i=1, \ldots, 277$; variable $j$ stands for the day, where $j=15 / 05 / 2007, \ldots, 15 / 11 / 2007$; and variable $k$ represents the temporal interval, where $k: 1,2, \ldots, K$. Note, the latter variable has a breadth $(z)$ that can be 30 minutes, 150 minutes or 450 minutes.

Filtering rule number 3 refers to a trading day that runs from 9.31.00AM to 5.00.59PM (i.e. 450 minutes). Thus, three large intra day phases were created, each made up of 150 minutes (2.5 hours): the first phase runs from 9.31.00AM to 12.00.59PM (morning), the second runs from 12.01.00PM to 2.30.59PM (lunch) and the third from 2.31.00PM to 5.00.59PM (evening). This allowed us to catch the main effects of intra day variability. In the same way, we created fifteen intra day phases made up of 30 minutes each and only one phase for the 450 minutes time frame. Within each of the different time frames, the tick by tick observations $T T_{i t}$ were aggregated and ordered according to the Time $t$ column. 
In our model, when $T T_{i t}=0$, it is associated to its transaction price $\left(P_{i t}\right)$ and to its trading volume $\left(T V_{i t}\right)$; when $T T_{i t}=1$, it is associated to its bid price $\left(B P_{i t}\right)$ and to its bid volume $\left(B V_{i t}\right)$; when $T T_{i t}=2$, it is associated to its ask price $\left(A P_{i t}\right)$ and to its ask volume $\left(A V_{i t}\right)$. Moreover, in the following equations the subscripts $i, k$ and $j$ stand for stock, interval and day respectively.

The model is based on the following variables:

\section{Trade size indicator $\left(t s_{i, k, j}\right)$}

The trade size is the average trading volume within every $k$ interval. It is obtained as:

$$
t s_{i, k, j}=\frac{1}{n_{i, k, j}} \sum_{t=1}^{n_{i, k, j}} T V_{i, t, j}
$$

where

- $t s_{i, k, j}=$ trade size;

- $T V_{i, t, j}=$ trading volume;

- $n_{i, k, j}$ total number of ticks (trades) that the stock $i$ experienced within the $k$ interval, of day $j$.

2. Order Flows Indicators $\left(O F_{i, k, j}\right)$

We consider the following alternative proxies of the order flows:

- Order intensity indicator $\left(\right.$ int $\left._{i, k, j}\right)$.

This indicator measures the frequency of bid/ask order within our $k$ intervals. It is:

$$
i n t_{i, k, j}=\frac{b n_{i, k, j}+a n_{i, k, j}}{2}
$$

where $b n_{i, k, j}$ is the number of ticks for bid orders and $a n_{i, k, j}$ is the number of ticks for ask orders, that the stock $i$ experienced within the $k$ interval, of day $j$.

- Interquote duration indicator $\left(i q d_{i, k, j}\right)$.

This indicator, as the following ones for the order flows, is based on the assumption that our time series are point processes (Hasbrouck, 2007). Bid and ask orders happen in discrete irregular time intervals. Our interquote indicators are based on the bid distance $B D_{i, t, j}$, in seconds, between the bid $T T_{i, t, j}$ and the bid $T T_{i, t-1, j}$ and the ask distance $A D_{i, t, j}$, in seconds, between the ask $T T_{i, t, j}$ and the ask $T T_{i, t-1, j}$. They are inspired to the idea of irregularly spaced data of Engel and Russel (2002). In particular, the interquote duration is:

$$
i q d_{i, k, j}=\frac{I Q D B_{i, k, j}+I Q D A_{i, k, j}}{2}
$$


where

- $I Q D B_{i, k, j}=\frac{\sum_{t=1}^{b n_{i, k, j}} B D_{i, t, j}}{b n_{i, k, j}}$ is the average interquote duration indicator on the bid side.

- IQD $A_{i, k, j}=\frac{\sum_{t=1}^{a n_{i, k, j}} A D_{i, t, j}}{a n_{i, k, j}}$ is the average interquote duration indicator on the ask side.

- Median Interquote duration indicator $\left(\right.$ iqdmed $_{i, k, j}$ ).

This indicator is obtained by replacing in the previous expression (3) the quantities $I Q D B_{i, k, j}$ and $I Q D A_{i, k, j}$ respectively with the median of the values $B D_{i, t, j}$ and $A D_{i, t, j}$.

- Minimum Interquote duration indicator $\left(i_{q d m i n}{ }_{i, k, j}\right)$.

This indicator is obtained by replacing in the previous expression (3) the quantities $I Q D B_{i, k, j}$ and $I Q D A_{i, k, j}$ with the minimum of the values $B D_{i, t, j}$ and $A D_{i, t, j}$.

- Weighted Interquote duration indicator $\left(w_{i q d_{i, k, j}}\right)$.

This indicator differs from $i q d_{i, k, j}$ because the time distances are weighted for their relative volumes. It is:

$$
w i q d_{i, k, j}=\frac{W I Q D B_{i, k, j}+W I Q D A_{i, k, j}}{2}
$$

where

- WIQDB $B_{i, k, j}=\frac{\sum_{t=1}^{b n_{i, k, j}} B D_{i, t, j} B V_{i, t, j}}{\sum_{t=1}^{b n_{i, k, j}} B V_{i, t, j}}$ is the weighted average interquote duration indicator on the bid side.

- WIQD $A_{i, k, j}=\frac{\sum_{t=1}^{a n_{i, k, j}} A D_{i, t, j} A V_{i, t, j}}{\sum_{t=1}^{a n_{i, k, j}} A V_{i, t, j}}$ is the average weighted interquote duration indicator on the ask side.

3. Relative bid-ask spread indicator $\left(\operatorname{rbas}_{i, k, j}\right)$.

It is a proxy of the trading costs and is calculated as

$$
\operatorname{rbas}_{i, k, j}=\frac{\left(A A P_{i, k, j}-A B P_{i, k, j}\right)}{\frac{1}{2}\left(A A P_{i, k, j}+A B P_{i, k, j}\right)}
$$

where

- $A A P_{i, k, j}=\frac{1}{a n_{i, k, j}} \sum_{t=1}^{a n_{i, k, j}} A P_{i, t, j}$ is the average ask price within the $k$ interval. - $A B P_{i, k, j}=\frac{1}{b n_{i, k, j}} \sum_{t=1}^{b n_{i, k, j}} B P_{i, t, j}$ is the average bid price within the $k$ interval.

4. Riskiness Indicators $\left(R_{i, k, j}\right)$.

We consider the following different proxies of risk:

- Statistical Volatility indicator $\left(\right.$ vol $\left._{i, k, j}\right)$.

As it is well known, we can easily calculate the statistical volatility as follows

$$
\operatorname{vol}_{i, k, j}=\sqrt{\frac{1}{\frac{z}{z^{\prime}}-1} \sum_{k=1}^{\frac{z}{z^{\prime}}}\left(r_{i, k, j}-\bar{r}_{i, k, j}\right)^{2}}
$$


where

- $r_{i, k, j}=\ln \left(\frac{P_{i, k, j}}{P_{i, k-1, j}}\right)$ is the log-return on a fifteen minutes $\left(z^{\prime}=15\right)$ interval basis $(k)$ for stock $i$ on day $j$. In this formulation, $P_{i, k, j}$ is the last trade price within the $k$ period and $P_{i, k-1, j}$ is the last trade price within the $k-1$ period. Note that the frequency $z^{\prime}=15$ is chosen to avoid the microstructure noise. - $\bar{r}_{i, k, j}$ is the average return within the original $k$ periods whose breadth $(z)$ can be alternatively 30 minutes, 150 minutes or 450 minutes.

- Garman-Klass Range (Garman and Klass, 1980) $\left(g k r_{i, k, j}\right)$.

After filtering for $T T_{i t}=0$, depending on the selected time frame, the high-frequency/intraday/daily indicator is

$g k r=\frac{0,511}{K} \sum_{k=1}^{K}\left(u_{k}-d_{k}\right)^{2}-\frac{0,019}{K} \sum_{k=1}^{K}\left[c_{k}\left(u_{k}+d_{k}\right)-2 u_{k} d_{k}\right]-\frac{0,383}{K} \sum_{k=1}^{K} c_{k}^{2}$

where

- $C_{k-1}$ closing price of the stock for each high-frequency/intraday/daily $k-1$ interval;

- $O_{k}$ opening price of the stock for each high-frequency/intraday/daily $k$ interval;

- $H_{k}$ highest price of the stock for each high-frequency/intraday/daily $k$ interval;

- $L_{k}$ lowest price of the stock for each high-frequency/intraday/daily $k$ interval;

- $C_{k}$ closing price of the stock for each high-frequency/intraday/daily $k$ interval;

- $c_{k}=\ln C_{k}-\ln O_{k}=\ln \frac{C_{k}}{O_{k}}$ is the normalized closing price;

- $o_{k}=\ln O_{k}-\ln C_{k-1}=\ln \frac{O_{k}}{C_{k-1}}$ is the normalized opening price;

- $u_{k}=\ln H_{k}-\ln O_{k}=\ln \frac{H_{k}}{O_{k}}$ is the normalized highest price;

- $d_{k}=\ln L_{k}-\ln O_{k}=\ln \frac{L_{k}}{O_{k}}$ is the normalized lowest price".

\section{Order Imbalance Indicator $\left(o i_{i, k, j}\right)$.}

We calculate the order imbalance as

$$
o i_{i, k, j}=\frac{A P R_{i, k, j}}{B P R_{i, k, j}}
$$

where

- $A P R_{i, k, j}=\frac{1}{a n_{i, k, j}} \sum_{t=1}^{a n_{i, k, j}} A V_{i, t, j}$ is the ask pressure.

- $B P R_{i, k, j}=\frac{1}{b n_{i, k, j}} \sum_{t=1}^{b n_{i, k, j}} B V_{i, t, j}$ is the bid pressure.

\section{Informational Events in the form of time series $\left(I E T S_{k, j}\right)$.}

This is the variable used in the intra day time frames: 
- Backwardation of the Euribor future (backwardation ${ }_{k, j}$ ).

The backwardation of the Euribor future revealed in the $k$ interval of day $j$ is

$$
\text { backwardation }_{k, j}=F_{{\text {may } 2008_{k, j}}}-F_{\text {dec } 2007_{k, j}}
$$

where

- $F_{\text {may } 2008_{k, j}}=$ May 2008 Euribor future close price in the k interval, of day $j$;

- $F_{d e c 2007_{k, j}}=$ December 2007 Euribor future close price in the k interval, of day $j$.

Keeping in mind that the implicit interest rate in the Euribor future is the difference between 100 and the future price $\mathrm{F}$, the subject variable is positive when the interest rates corresponding to the shorter maturity are higher than the interest rates corresponding to the longer maturity. More directly, backwardation $k, j$ is positive when market participants perceive a lack of the underlying asset (short term interbank deposits). In fact, backwardation $k, j$, on a daily basis, is always negative from the starting date of our analysis (the $15^{\text {th }}$ of May 2007) until the $16^{\text {th }}$ of August 2007; after this date it becomes steadily more positive. This variable helps us to capture, on an intra day basis, when it was that the banks became aware of the spread of the sub-prime crisis (proxy of a form of private information, because retail traders are not supposed to be able to obtain these data).

- TED spread $\left(\right.$ ted $\left._{j}\right)$.

It is calculated as

$$
\operatorname{ted}_{j}=3 m L I B O R_{j}-3 m t r_{j}
$$

where

- $3 m L I B O R_{j}=3$-months LIBOR, in the day $\mathrm{j}$;

- $3 m t r_{j}=3$-months treasury rate, in the day $\mathrm{j}$.

It is the signal of the difference of credit risk premium between a risky asset $(3 m L I B O R)$ and a risk-free asset $(3 m t r)$, in the day j.

7. Informational Events in the form of dummies for news $\left(I E N_{k, j}\right)$.

Together with backwardation $_{k, j}$, on a daily basis we also consider the following informations in the form of dummies (relevant news from the italian provider ANSA):

- 23/06/2007 ISE and LSE merger announcement ( $d 23 j u n)$. On this date, the Board of Borsa Italiana S.p.A. and of the London Stock Exchange Group plc announced its agreement about a recommended offer from the LSE to the shareholders of Borsa Italiana. Starting from that date the two Stock Exchanges gradually moved together toward a merger;

- 16/08/2007 Sub prime earthquake: down also Fiat and Autogrill (d16ago);

- 18/09/2007 FED, relevant cut of interest rate to 4,75 percent (d18sep); 
- 31/10/2007 FED, cut of interest rate to 4,5 percent (d31oct).

\subsection{The empirical equation}

Our general empirical equation can be written as:

$$
\begin{aligned}
\log _{t, k, j} & =a_{i}+\sum_{t=1}^{T} \alpha_{t} \log _{\text {to }} s_{i, k-t, j}+\beta_{1} O F_{i, k, j}+\beta_{2} \text { rbas }_{i, k, j} \\
& +\beta_{3} R_{i, k, j}+\beta_{4} \operatorname{logoi} i_{i, k, j}+\beta_{5} I E T S_{k, j}+\beta_{6} I E N_{k, j}+\varepsilon_{i, k, j}
\end{aligned}
$$

where the error term, $\varepsilon_{i, k, j}$, is supposed to be both arbitrary heteroskedastic and arbitrary intra-groups correlated (the errors are not independent within individuals, although they are independent between individuals). Note that we use the logarithm transformation for trade size, order flows and order imbalance indicators. This in order to reduce positive skewness in the distributions, and interpreted all the parameter estimates as elasticities. To made results comparable, the riskiness indicator measured by the Garman-Klass Range is multiplied by 100 .

Depending on the time frame considered, some differences in the model (11) specification emerge. As far as dynamics is concerned, we use four lags $(T=4)$ in the 30 and 450 minutes frames, and two lags $(T=2)$ in the 150 minutes frame. We believe these lags capture the quite weekly operating period in the daily frame, and the variations over the course of the day (opening, middle of the day and closing) in the 30 and 150 minutes frames. Risk is measured by the Garman-Klass Range in the 30 minutes frame, and by statistical volatility indicator in the 150 and 450 minutes frames. Specific days dummies (included in the variable IEN) are, of course, considered in the daily frame only. In particular, the news considered are: the $23^{\text {rd }}$ of June in Book1, the $16^{\text {th }}$ of August in Book 2 and the $31^{\text {th }}$ of October in Book 3 (we checked also the $18^{\text {th }}$ of September, but the first reduction of interest rate is not significant).

Existing literature offers little consensus in selecting the indicator which better represents the riskiness of a stock. Moreover, the order flows thickness may be expressed in terms of new bid/ask orders, in a time unit, as well as in terms of time distance between one order and the following. We define a benchmark model (called model $A$ ) in which order flows are measured by the order intensity indicator. We then carry out a number of robustness checks by varying the measures of OF, R, and IETS. In particular, in the 30 minutes frame, we also try statistical volatility indicator in place of the Garman-Klass range indicator (model $A_{-} V O L$ ); vice-versa, in the 150 and 450 minutes frames, we replace $v o l$ for $g k r$ (model $A_{-} G K R$ ). In all the time frames we alternatively replace the order intensity measure of order flows with either the average or median or minimum or weighted average interquote duration indicators (models $A_{-} I Q D, A_{-} I Q D M E D, A_{-} I Q D M I N, A_{-} W I Q D$, respectively). Finally, in the daily frame, we check the effect of replacing backwardation by TED spread (model $A_{-} T E D$ ).

The estimation method is the fixed effects panel estimator with robust standard errors to both arbitrary heteroskedasticity and arbitrary intra-groups correlation. It is well known that some of the variables affecting the trade size (e.g. relative bid-ask spread, riskiness and order imbalance) are simultaneously affected by the trade size as 
well. These endogenous variables are instrumented with proper lags (up to four lags in 30 and 450 minutes frames; up to two lags in 150 minutes frame). Dynamics could also create an endogeneity problem: the fixed effects estimator applied to dynamic panels is biased downwards; it is inconsistent as $\mathrm{N}$ becomes large; the inconsistency is of order $1 /(T-1)$. Since we have, on average in each sub-samples, $T>470$, we are in the case the fixed effects estimator becomes consistent as $\mathrm{T}$ becomes large (Nickell, 1981). We also try IV (2SLS) of Anderson and Hsiao (1982) on the first-differencing transformation. In this case, the lagged dependent variable is instrumented by the level in $t-4$ of trade size. Results are robust, despite, as well known, less precise.

\section{Results}

Our results provide empirical findings and also form the basis for a discussion of some other related issues. The main empirical results can be summarized as follows (estimates are shown in Appendix 3):

1. main drivers of trade size: we found robust relationships between the trade size and our explanatory variables. In Book1, these relationships are not always significant but, when the PTT is enhanced (in Book2 and especially in Book3), their sign remains resiliently stable, independent of the time frame considered. The trade size is:

(a) positively linked to its lags (always significant, except for some lags in the daily estimates), as was expected.

(b) positively linked to the order intensity (always significant). This could mean that when order flows increase, in the time unit, we might expect to observe an increase in the trade size, because: a) some traders may possess private information; in order to exploit it, he/she inserts more orders into the book, that are larger in size, thus concluding with bigger trades; b) the increasing number of orders is 'emotionally' interpreted by traders as a sign that some of them could possess private information; so they assume an imitative behaviour and take part in the trading pressure.

(c) negatively linked to the bid-ask spread (often significant; always in Book3), as was expected.

(d) negatively linked to the risk indicator (nearly always significant in the intra day time frames, with the only exception being in Book 1 in the 30 minutes time frame. This result, opposite compared to the existing literature, is strongly confirmed on the intra-day time frame, while on the daily basis the link is rarely significant. We could argue that the persistent (negative) relationship uncovered for the intra day basis indicates that Italian traders are mainly averse to risk and that as risk increases they tend to freeze their trading activity, reducing their trade size.

(e) positively linked to backwardation (very often significant in the intra day time frames, but less significant on the daily basis). 
2. consequences of the increases in PTT. Moving from B1 to B3, independent of the time frame considered, our models are better instrumented (as far as the specification tests are concerned) and show clearer results (for the mentioned interconnections 1, 2, 3, 4 and 5). For the intra day models we observed significant changes in the absolute values of the following significant parameters:

- the positive relationship between trade size and order intensity becomes weaker: the absolute value of the parameter decreases; generally with a significant difference. Within the overall analysis, this is the only piece of evidence indicated by the intra day estimates and confirmed on the daily basis. When the market is more transparent and, as in 'Book Profondo', all the traders are allowed to see all orders for each price level, we can reasonably expect that: a) the traders who possess private information are more cautious in quoting and trading, breaking up the size of their orders (e.g. by means of iceberg orders) and repressing the size of their trades; b) all the other traders, thanks to better PTT, are able to understand whether the trading pressure is real or fictitious, avoiding increases in the trading size without sufficient grounds; c) moreover, all the traders, especially retail traders, may identify some signals of risk from the order book disclosed (for example, evidence of iceberg orders), choosing to exit from the market and cancelling their quotes. This should mean that, with greater PTT, a smaller number of quotes are transformed into trades. As a proof of this phenomenon, from the descriptive statistics (see Appendix 2) we observe that the proportion of the quotes that become transformed into trades moves close to 23 per cent within the B1 period and to 20 per cent within the B2 and B3 periods.

- the negative relationship between the trade size and the bid-ask spread becomes feebler: the absolute value of the parameter decreases and the difference is significant for both of the intra day general models. Even if the inventory and the asymmetrical information paradigms are not appropriate for an order driven market, we can argue that when the market conditions are less transparent, the bid-ask spread widens (Biais, 1993). It appears that PTT works as a mean of this transparency because we can see from the descriptive statistics that the movement from B1 to B3 causes the overall average bid-ask spreads to reduce. In relation to this, our estimates show that the increase in PTT contributes to the bringing to an end of the negative effects that bid-ask spreads have upon trade sizes. Definitely the transparency of the book seems to be compensating for the 'indirect opacity' related to a high bid-ask spread. That is to say that high PTT levels may also allow wide trades for illiquid stocks.

- the negative relationship between the trade size and the risk indicator (GKR or VOL) reduces its effects: the absolute value of the parameter decreases, even if a significant difference is only detected in the 150 minutes time frame. When a market is not transparent, we can argue that traders, especially the retail ones, may also repress their trading size to compensate uncertainty. 
When a market improves its transparency, it is reasonable that traders are able to downsize their risk aversion. A more informative and reliable order book may cause traders to be more confident about their understanding of the trading process. This could lead them to consider trades of higher trade sizes even for risky stocks. Italian traders have mainly been described as being risk averse; as risk increases they tend to freeze their trading sizes; nevertheless, as the market becomes more transparent Italian investors appear to be more willing to assume more 'informed' risky-positions.

3. relevance of informational events. The backwardation is often significant and always attests a positive contribution to the trade size, despite the fact that this indicator inverts its sign in the the first half of August (see Appendix 2 for the descriptive statistics): both the abundance and the reductions of interbank liquidity can, in the short term, provide an informative signal that institutional traders are able to exploit, resulting in increases in trade size. Proof of this informative power of backwardation, in the intra day time frame, comes from observing the daily models where this power is often disturbed by information event dummies (especially 'bad news dummies', like the news of strong downtrends published in the ISE and/or Federal Reserve announcements).

Marginally, our estimates shed some light on the appropriateness of the indicators used in our estimates. Comparing the different models, we have provided evidence on which indicators are interchangeable, and which ones are not. More precisely, for the indicators of order flows, the order intensity and the inter quote duration are completely interchangeable, no matter how they are calculated (mean, median, minimum or weighted), as they capture the relationship between the order vivacity and the trade size with the same effectiveness. We selected order intensity as it is easier to comprehend. Conversely, as far as the risk indicators are concerned, GKR and statistical volatility are not interchangeable; at least on the very short term. In the 30 minutes time frame, the MODEL $A_{-} V O L$ reveals weaker specification tests. Moreover, some important relationships (i.e. between trade size and the bid-ask spread in B2 and B3) loose significance when compared with all the other Models based on the GKR ${ }^{2}$

\section{Concluding remarks and future research}

Our main empirical findings show that intra day models are more effective than the daily models at describing the behaviour of traders after an enhancement of PTT. The main drivers of the trade size, used as an expression of this behaviour, are generally significant and most of the signs of the relationships are coherent with previous literature (in particular, for order flows and bid-ask spread). On the contrary, we show risk to have

\footnotetext{
${ }^{2}$ The estimates of the MODEL $A_{-} V O L$ were conducted on a smaller number of observations ( $n=41,072)$ compared to the others $(n=64,094)$ due to the specific way in which the statistical volatility was computed; we also ran, therefore, the estimates within the same subset of observations and the results absolutely confirmed the previous findings of MODEL A and of MODEL $A_{-} V O L$. On the contrary, in the 150 minutes time frame, the benchmark Model exploits risk via statistical volatility while the MODEL $A_{-} G K R$ shows weaker estimates.
} 
a negative link with trade size, and this represents the aversion of the Italian traders to risk. This result is significant on the intra day basis and seems to be in contrast with the findings of a previous study that referred to US stock markets. In the short term, both the abundance and the reductions of the interbank liquidity, measured by backwardation, are proved to act as an informative signal that institutional traders exploit to increase their trade size. Information events, in the form of news, are shown to affect the trade size in an unconventional manner: before the spread of news (e.g. the ISE-LSE merger) or only after an unusual shock (e.g. the second unexpected interest rate cut issued by the FED).

As an overall effect of the enhancement of PTT in the ISE equity markets, we argue that (intra day) traders operating in a more transparent market become more reticent and less risk averse: if they are informed (institutional) traders, they tend to hide their intentions, prudently repressing the size of their trades; if they are noninformed (retail) intra day traders, they are able to better understand if a trading pressure is real or fictitious, in turn controlling emotional imitative behaviours; the latter type of trader also runs the chance of refusing opaque trading and cancelling orders. Moreover, the increased level of disclosure of the order book permits traders to downsize their level of risk aversion, reducing that uncertainty that is able, under the condition of opacity, to break trading activity. A more informative order book induces traders to act confidently on their knowledge of the trading process, dealing with higher trade sizes even for risky or illiquid stocks.

In the near future, we intend to further this research by identifying the specific commonalities (as described by Chordia, Roll and Subrahmanyam, 2000) within the overall list of the shares used; we will look for differences due to market capitalization, business sector and beta. Moreover, we aim to develop further the investigation into the unexpected negative relationship between trade size and risk in order to try to understand whether or not it is due to a time frame peculiarity, or if it is a consequence of a specific national behaviour.

\section{References}

Aminud, Y. And H. Mendelson (1980), "Dealership markets: Market making with inventory", Journal of Financial Economics, 8, pp. 31-53.

Anderson, T. And C. Hsiao (1982;), "Formulation and Estimation of Dynamic Models using Panel Data", Journal of Econometrics, 18, pp. 47-82.

BAndi, F. And J. R. Russell (2006), "Separating microstructure noise from volatility", Journal of Financial Economics, 79, pp. 655-692.

Barber, B. And T. Odean (2008), "All that glitters: The Effect of Attention and News on the Buying Behavior of Individual and Institutional Investors", Review of Financial Studies, 21(2), pp. 785-818.

Baum, C., M. Schaffer and S. Stillman (2003), "Instrumental variables and GMM: Estimation and testing", The Stata Journal, 3(1), pp. 1-31. 
Baum, C., M. Schaffer and S. Stillman (2007), "Enhanced routines for instrumental variables/GMM estimation and testing", Boston College Economics Working Paper, 667.

BiAis, B. (1993), "Price formation and equilibrium liquidity in fragmented and centralized markets", Journal of Finance, 48, pp. 157-185.

Bohemer, E., G. SaAr and L. Yu (2005), "Lifting the Veil: An Analysis of the Pre-trade Transparency at the NYSE", Journal of Finance, 60(2), pp. 783-815.

Brennan, M. and A. Subrahmanyam (1998), "The determinants of average trade size", Journal of Business, 71(1), pp. 1-25.

Chan, Y. (2000), "The price impact of trading on the stock exchange of Hong Kong", Journal of Financial Markets, 3, pp. 1-16.

Chordia, T., R. Roll and A. Subrahmanyam (2000), "Commonality in liquidity", Journal of Financial Economics, 56, pp. 3-28.

Chordia, T., R. Roll and A. Subrahmanyam (2001), "Market Liquidity and Trading Activity", Journal of Finance, 56(2), pp. 501-530.

Chowdhry, B. And V. NANda (1991), "Multi-market trading and market liquidity", Review of Financial Studies, 4, pp. 483-511.

Engel, R. AND J. Russel (2002), "Autoregressive conditional duration: a new model for irregularly spaced transaction data", Econometrica, 66(5), pp. 1127-1162.

Focault, T., S. Moinas and E. Theissen (2007), "Does Anonymity matter in Electronic Limit Order Markets?", Review of Financial Studies, 20, pp. 1707-1747.

Forster, M. And T. George (1992), "Anonymity in securities markets", Journal of Financial Intermediation, 2, pp. 168-206.

Garman, M. And M. Klass (1980), "On the estimation of security price volatilities from historical data", Journal of Business, 53(1), pp. 67-78.

Hansen, L. (1982), "Large sample properties of generalized method of moments estimators", Econometrica, 50(3), pp. 1029-1054.

Hansen, P. And A. Lunde (2006), "Realized variance and market microstructure noise", Journal of Business and Economic Statistics, 24(2), pp. 127-161.

Harris, J. And P. Schultz (1997), "The importance of firm quotes and rapid executions: evidence from the January 1994 SOES rule change", Journal of Financial Economics, 45, pp. 135-166.

HARRIS, L. (1996), "Does a large minimum price variation encourage order exposure?", Unpublished manuscript, University of Southern California. 
Hasbrouck, J. (2007), Empirical Market Microstructure, Oxford University Press.

Huang, R. And H. Stoll (1996), "Dealer versus auction markets: a paired comparison of execution costs on NASDAQ and the NYSE", Journal of Financial Economics, 41 , pp. $313-357$.

Kleibergen, F. and R. PaAp (2006), "Generalized reduced rank tests using the singular value decomposition", Journal of Econometrics, 127(1), pp. 97-126.

Kleibergen, F. And M. Schaffer (2007), "RANKTEST: Stata module to testing the rank of a matrix using the Kleibergen-Paap rk statistic", Available at: http://ideas.repec.org/c/boc/bocode/s456865.html.

Lin, J., G. Sanger And G. Booth (1995), "Trade size and components of the bid-ask spread", Review of Financial Studies, 8, pp. 1153-1183.

Lo, A. And W. WANG (2001), "Trading volume: definitions, data analysis and implications of portfolio theory", The Review of Financial Studies, 13(2), pp. 257-300.

Madhavan, A. (2000), "Market Microstructure: A survey", Journal of Financial Markets, 3, pp. 205-258.

Nickell, S. (1981), "Biased in dynamic Models with Fixed Effects", Econometrica, 49 , pp. $1417-1426$.

O'Hara, M. (1995), Market microstructure theory, Basil Blackwell, Cambridge.

Simaan, Y., D. Weaver and D. Withcomb (2003), "Market Maker Quotation Behaviour and Pre-trade Transparency", Journal of Finance, 50, pp. 1247-1267.

Stoll, H. (1976), "Dealer inventory behavior: An empirical investigation of Nasdaq stocks", Journal of Financial and Quantitative Analysis, 11, pp. 359-380.

Stoll, H. (1978), "The supply of dealer services in securities markets", Journal of Finance, 33, pp. 1133-1151.

Theissen, E. (2003), "Trader anonymity, Price Formation and Liquidity", European Finance Review, 7, pp. 1-26. 


\section{Appendix 1: Filtering rules to convert a tick by tick data set into a panel structure}

Table 2: Cleaning guidelines: Cases for $\mathrm{tt}=0$ (trades)

\begin{tabular}{|c|c|c|c|c|c|c|c|}
\hline Case & Stock & $\operatorname{Day}_{j}$ & Time $t$ & $\mathrm{P}_{i t}$ & $\mathrm{~V}_{i t}$ & $\mathrm{TT}_{t t}$ & \\
\hline $\begin{array}{l}1: \\
\mathrm{tt}=0 \\
\text { same price } \\
\text { different volume }\end{array}$ & PG.MIL & $15 / 05 / 2007$ & 9.05 .33 & 0.4615 & 9995 & 0 & $\begin{array}{l}\text { At that time insert: } \\
\text { - average of prices; } \\
\text { - sum of volumes. }\end{array}$ \\
\hline $\begin{array}{l}2: \\
\mathrm{tt}=0 \\
\text { different price } \\
\text { different volume }\end{array}$ & $\begin{array}{l}\text { PG.MIL } \\
\text { PG.MIL } \\
\text { PG.MIL } \\
\text { PG.MIL } \\
\text { PG.MIL } \\
\text { PG.MIL } \\
\text { PG.MIL } \\
\text { PG.MIL } \\
\text { PG.MIL } \\
\text { PG.MIL } \\
\text { PG.MIL } \\
\text { PG.MIL }\end{array}$ & $\begin{array}{l}15 / 05 / 2007 \\
15 / 05 / 2007 \\
15 / 05 / 2007 \\
15 / 05 / 2007 \\
15 / 05 / 2007 \\
15 / 05 / 2007 \\
15 / 05 / 2007 \\
15 / 05 / 2007 \\
15 / 05 / 2007 \\
15 / 05 / 2007 \\
15 / 05 / 2007 \\
15 / 05 / 2007\end{array}$ & $\begin{array}{l}9.49 .00 \\
9.49 .00 \\
9.49 .00 \\
9.49 .00 \\
9.49 .00 \\
9.49 .00 \\
9.49 .00 \\
9.49 .00 \\
9.49 .00 \\
9.49 .00 \\
9.49 .00 \\
9.49 .00\end{array}$ & $\begin{array}{l}0.46 \\
0.4605 \\
0.46 \\
0.4605 \\
0.4605 \\
0.46 \\
0.46 \\
0.46 \\
0.4605 \\
0.4605 \\
0.46 \\
0.4605\end{array}$ & $\begin{array}{l}44467 \\
16525 \\
39700 \\
19762 \\
27295 \\
100 \\
89000 \\
10000 \\
50000 \\
59000 \\
89171 \\
7738\end{array}$ & $\begin{array}{l}0 \\
0 \\
0 \\
0 \\
0 \\
0 \\
0 \\
0 \\
0 \\
0 \\
0 \\
0\end{array}$ & $\begin{array}{l}\text { At that time insert: } \\
\text { - average of prices; } \\
\text { - sum of volumes. }\end{array}$ \\
\hline $\begin{array}{l}3: \\
\mathrm{tt}=0 \\
\text { same price } \\
\text { same volume }\end{array}$ & & & & & & & $\begin{array}{l}\text { More difficult to find but } \\
\text { when it happens it can } \\
\text { be due to iceberg } \\
\text { orders. For this reason } \\
\text { filtering rules are identical } \\
\text { to those previously shown: } \\
\text { - average of prices; } \\
\text { - sum of volumes. }\end{array}$ \\
\hline
\end{tabular}


Table 3: Cleaning guidelines: Cases for $t \mathrm{t}=1$ (bid) or $\mathrm{tt}=2$ (ask)

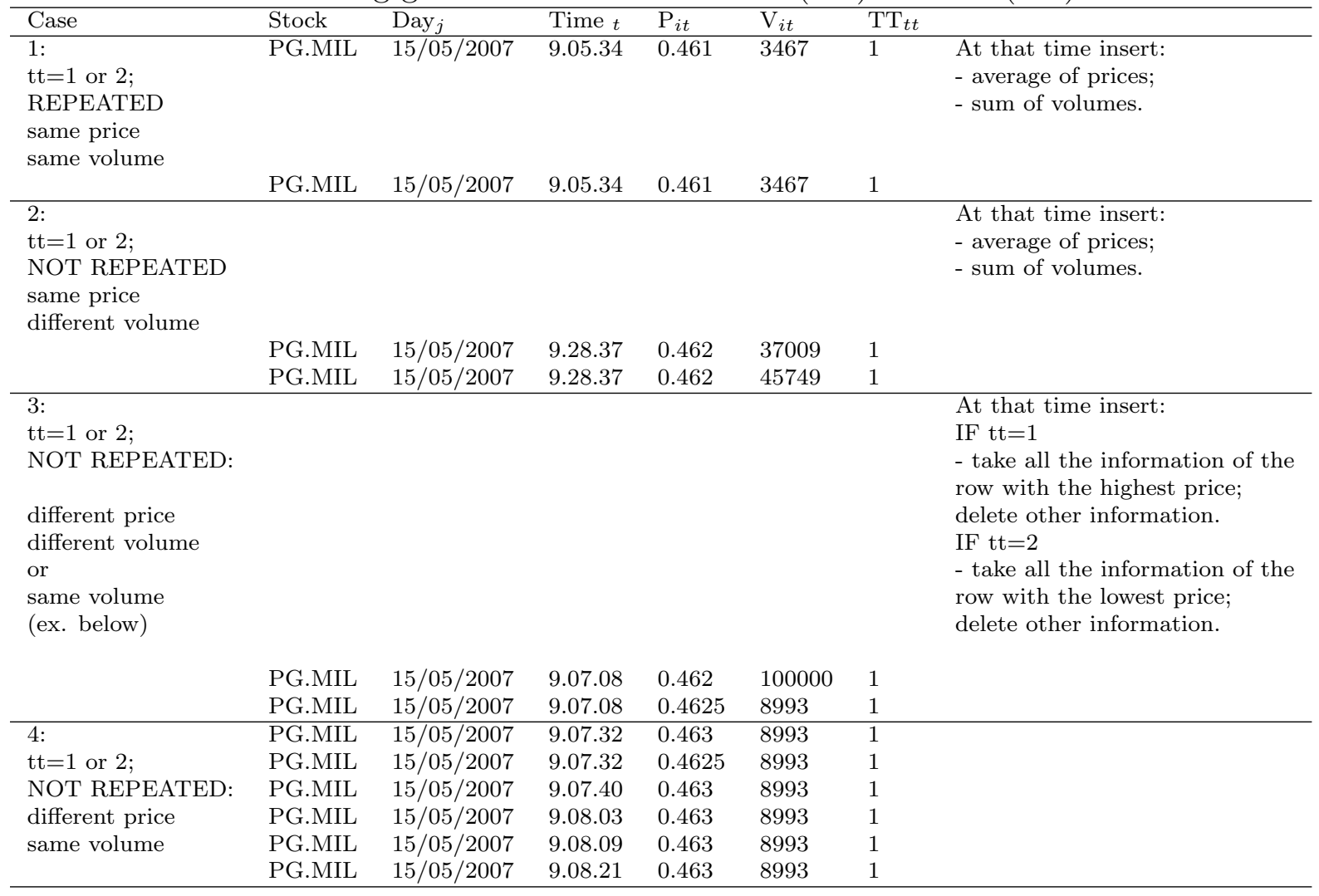




\title{
Appendix 2: Descriptive statistics
}

Table 4: Descriptive statistics - 30 minutes

\begin{abstract}
$\mathrm{APR}=$ ask pressure; $\mathrm{BPR}=$ bid pressure; $\mathrm{INT}=$ ordern intensity; $\mathrm{bn}=$ number of ticks for bid orders; an=number of ticks for ask orders; wiqd=weighted interquote duration; iqd=interquote duration; iqdmed=median interquote duration; iqdmin=minimum interquote duration; backward=backwardation. In Book 1 the statistics are computed on NT=106,820 (total number of observations), $\mathrm{N}=267$ (total number of stocks), $\mathrm{T}=400$ (average number of time periods); in the statistical volatility indicator case the total number of observations fall to 76861 (about 287 average number of time periods) because lags are used in the computation.]
\end{abstract}

\begin{tabular}{|c|c|c|c|c|c|c|}
\hline \multicolumn{7}{|c|}{ Book1 } \\
\hline & 1st Q & Median & 3rd Q & IQR & Mean & $\mathrm{SD}$ \\
\hline ts & 482.5 & 1171.068 & 3191.187 & 2708.687 & 3691.635 & 10154.67 \\
\hline $\mathrm{n}$ & 4 & 11 & 31 & 27 & 28.74771 & 50.34952 \\
\hline TV & 2500 & 13790 & 72808.5 & 70308.5 & 184875.7 & 847899.4 \\
\hline vol & 0.0006612 & 0.0016091 & 0.0032996 & 0.0026384 & 0.0026108 & 0.0033366 \\
\hline $\mathrm{gkr}$ & 0 & $3.64 \mathrm{E}-06$ & 0.0000221 & 0.0000221 & 0.0000718 & 0.0007316 \\
\hline APR & 417.6026 & 1045.479 & 3002.716 & 2585.113 & 4647.283 & 21345.28 \\
\hline BPR & 405.3917 & 1029.599 & 2994.167 & 2588.775 & 4450.505 & 16086.12 \\
\hline INT & 24 & 66 & 159 & 135 & 122.9534 & 155.3525 \\
\hline bn & 24 & 66 & 159 & 135 & 122.9644 & 155.3533 \\
\hline an & 24 & 66 & 158 & 134 & 122.9424 & 155.3675 \\
\hline wiqd & 10.70605 & 25.76458 & 71.17729 & 60.47124 & 77.51958 & 195.7756 \\
\hline iqd & 11.2625 & 26.86765 & 73 & 61.7375 & 76.58201 & 188.8773 \\
\hline iqdmed & 4 & 10 & 28 & 24 & 44.16685 & 172.4986 \\
\hline iqdmin & 1 & 1 & 1 & 0 & 12.02583 & 137.7318 \\
\hline \multirow[t]{3}{*}{ backward } & -0.1000061 & -0.0800018 & -0.0400009 & 0.0600052 & -0.0753538 & 0.0345086 \\
\hline & & & Book2 & & & \\
\hline & 1st Q & Median & 3rd Q & IQR & Mean & SD \\
\hline ts & 433.9474 & 1096 & 2940.444 & 2506.497 & 3352.912 & 9105.54 \\
\hline $\mathrm{n}$ & 3 & 10 & 30 & 27 & 26.29057 & 45.192 \\
\hline TV & 2096 & 11581 & 61004 & 58908 & 147854.4 & 667266.8 \\
\hline vol & 0.0007534 & 0.0018728 & 0.0038905 & 0.0031371 & 0.0030788 & 0.0039713 \\
\hline gkr & 0 & $3.68 \mathrm{E}-06$ & 0.0000281 & 0.0000281 & 0.0000879 & 0.0007382 \\
\hline APR & 385.419 & 946.26 & 2612.214 & 2226.795 & 3830.747 & 15275.03 \\
\hline BPR & 381.3044 & 940.6102 & 2600.735 & 2219.43 & 3792.491 & 14125.75 \\
\hline INT & 23 & 66 & 166 & 143 & 126.1742 & 159.056 \\
\hline bn & 23 & 66 & 166 & 143 & 126.187 & 159.046 \\
\hline an & 23 & 66 & 166 & 143 & 126.1614 & 159.0848 \\
\hline wiqd & 10.25704 & 25.85086 & 73.89018 & 63.63315 & 83.61446 & 223.5503 \\
\hline iqd & 10.76024 & 26.85075 & 75.6087 & 64.84846 & 82.31102 & 216.1881 \\
\hline iqdmed & 4 & 10 & 29 & 25 & 48.24927 & 199.6314 \\
\hline iqdmin & 1 & 1 & 1 & 0 & 14.67284 & 166.3191 \\
\hline \multirow[t]{3}{*}{ backward } & -0.1100006 & -0.0599976 & 0.0800018 & 0.1900024 & -0.0318872 & 0.0895535 \\
\hline & & & Book3 & & & \\
\hline & 1st Q & Median & 3rd Q & IQR & Mean & SD \\
\hline ts & 466.6667 & 1097.833 & 2813.345 & 2346.678 & 3233.554 & 9909.999 \\
\hline $\mathrm{n}$ & 3 & 10 & 29 & 26 & 25.64137 & 44.59837 \\
\hline TV & 2100 & 11378.5 & 56665 & 54565 & 144724.9 & 759018.4 \\
\hline vol & 0.0007698 & 0.0018893 & 0.0038912 & 0.0031213 & 0.0030605 & 0.0039362 \\
\hline gkr & 0 & $4.01 \mathrm{E}-06$ & 0.0000291 & 0.0000291 & 0.0000949 & 0.0008102 \\
\hline APR & 422.2113 & 995.9361 & 2640.783 & 2218.571 & 4555.043 & 26175.03 \\
\hline BPR & 399.4898 & 961.875 & 2562.55 & 2163.06 & 4289.12 & 18328.26 \\
\hline INT & 21 & 63 & 163 & 142 & 121.6524 & 154.2853 \\
\hline bn & 21 & 63 & 164 & 143 & 121.6666 & 154.2811 \\
\hline an & 21 & 63 & 164 & 143 & 121.6383 & 154.3078 \\
\hline wiqd & 10.38315 & 26.99399 & 80.47823 & 70.09508 & 92.82041 & 259.3969 \\
\hline iqd & 10.88724 & 28.01563 & 82.25 & 71.36276 & 91.45066 & 252.7157 \\
\hline iqdmed & 4 & 10 & 30 & 26 & 54.32902 & 233.5966 \\
\hline iqdmin & 1 & 1 & 1 & 0 & 18.33301 & 197.9085 \\
\hline backward & 0.1600037 & 0.1999969 & 0.2300034 & 0.0699997 & 0.1911549 & 0.0595456 \\
\hline
\end{tabular}


Table 5: Descriptive statistics - 150 minutes

\begin{abstract}
[ts=trade size; $\mathrm{n}=$ total number of trade ticks; $\mathrm{TV}=$ trading volume; vol=statistical volatility; $\mathrm{gkr}=\mathrm{Garman}-\mathrm{Klass}$ range;
$\mathrm{APR}=$ ask pressure; $\mathrm{BPR}=$ bid pressure; INT=ordern intensity; $\mathrm{bn}=$ number of ticks for bid orders; an=number of ticks for ask orders; wiqd=weighted interquote duration; iqd=interquote duration; iqdmed=median interquote duration; iqdmin=minimum interquote duration; backward=backwardation. In Book 1 the statistics are computed on NT=106,820 (total number of observations), $\mathrm{N}=267$ (total number of stocks), $\mathrm{T}=400$ (average number of time periods); in the statistical volatility indicato case the total number of observations fall to 76861 (about 287 average number of time periods) because lags are used in the computation.]
\end{abstract}

\begin{tabular}{|c|c|c|c|c|c|c|}
\hline \multicolumn{7}{|c|}{ Book1 } \\
\hline & 1st Q & Median & 3rd Q & IQR & Mean & SD \\
\hline ts & 585.6617 & 1275.583 & 3260.35 & 2674.688 & 3518.609 & 7274.547 \\
\hline $\mathrm{n}$ & 21 & 58 & 161 & 140 & 143.8251 & 233.1228 \\
\hline $\mathrm{TV}$ & 16322 & 79549 & 397656 & 381334 & 926663.6 & 3861745 \\
\hline vol & 0.0015584 & 0.0024244 & 0.0038831 & 0.0023248 & 0.0031862 & 0.0087289 \\
\hline $\mathrm{gkr}$ & $3.07 \mathrm{E}-06$ & 0.0000141 & 0.00004 & 0.000037 & 0.0000683 & 0.0004338 \\
\hline APR & 500.3556 & 1129.221 & 3153.039 & 2652.684 & 4667.841 & 16391.23 \\
\hline BPR & 490.3733 & 1135.523 & 3191.605 & 2701.232 & 4505.454 & 13966.09 \\
\hline INT & 134 & 353 & 793 & 659 & 610.0701 & 721.7915 \\
\hline bn & 134 & 353 & 793 & 659 & 610.0575 & 721.7534 \\
\hline an & 134.5 & 353 & 793 & 658.5 & 610.0827 & 721.842 \\
\hline wiqd & 10.65024 & 23.63223 & 61.51342 & 50.86318 & 59.9017 & 110.7211 \\
\hline iqd & 11.13768 & 24.62158 & 63.46023 & 52.32255 & 60.36752 & 106.5999 \\
\hline iqdmed & 4 & 8 & 20 & 16 & 23.77514 & 61.1656 \\
\hline iqdmin & 1 & 1 & 1 & 0 & 1.398687 & 12.93779 \\
\hline \multirow[t]{3}{*}{ backward } & -0.0999985 & -0.0800018 & -0.0499954 & 0.0500031 & -0.0767093 & 0.0332695 \\
\hline & & & Book2 & & & \\
\hline & 1st Q & Median & 3rd Q & IQR & Mean & SD \\
\hline ts & 545.3256 & 1219.146 & 3065.895 & 2520.569 & 3312.222 & 6979.244 \\
\hline $\mathrm{n}$ & 19 & 55 & 157 & 138 & 131.9297 & 201.8179 \\
\hline TV & 14125 & 68603 & 338912 & 324787 & 750686.6 & 2985258 \\
\hline vol & 0.0017944 & 0.0028458 & 0.0046359 & 0.0028416 & 0.0036766 & 0.0030291 \\
\hline gkr & $2.75 \mathrm{E}-06$ & 0.0000178 & 0.0000544 & 0.0000517 & 0.0000869 & 0.0003663 \\
\hline APR & 465.4796 & 1046.091 & 2772.343 & 2306.863 & 3907.44 & 12160.38 \\
\hline BPR & 456.8173 & 1030.408 & 2724.44 & 2267.623 & 3860.286 & 11931.65 \\
\hline INT & 132 & 361 & 854 & 722 & 631.2035 & 727.2923 \\
\hline bn & 132 & 361 & 854 & 722 & 631.1893 & 727.2572 \\
\hline an & 132 & 361 & 854 & 722 & 631.2177 & 727.3407 \\
\hline wiqd & 9.825535 & 23.15388 & 63.78135 & 53.95581 & 65.72079 & 141.8265 \\
\hline iqd & 10.31501 & 24.16936 & 65.06522 & 54.75021 & 65.70221 & 136.4272 \\
\hline iqdmed & 4 & 8.5 & 21 & 17 & 26.78179 & 92.83074 \\
\hline iqdmin & 1 & 1 & 1 & 0 & 1.797501 & 24.60997 \\
\hline \multirow[t]{3}{*}{ backward } & -0.1100006 & -0.0599976 & 0.0899963 & 0.1999969 & -0.0314927 & 0.0899512 \\
\hline & & & Book3 & & & \\
\hline & 1st Q & Median & 3rd Q & IQR & Mean & $\mathrm{SD}$ \\
\hline ts & 577.6316 & 1216.118 & 2942.643 & 2365.011 & 3166.304 & 7134.682 \\
\hline $\mathrm{n}$ & 17 & 53 & 155 & 138 & 128.6791 & 198.4082 \\
\hline $\mathrm{TV}$ & 14191 & 66789 & 313115 & 298924 & 734536.2 & 3284482 \\
\hline vol & 0.0018276 & 0.0028577 & 0.0045771 & 0.0027495 & 0.0036856 & 0.0032091 \\
\hline gkr & $3.12 \mathrm{E}-06$ & 0.0000186 & 0.0000557 & 0.0000525 & 0.0001033 & 0.0005964 \\
\hline APR & 503.9208 & 1086.522 & 2782.509 & 2278.588 & 4663.406 & 24175.77 \\
\hline BPR & 478.5 & 1050.448 & 2709.689 & 2231.189 & 4397.265 & 16496.15 \\
\hline INT & 120 & 347 & 843 & 723 & 607.0928 & 701.6279 \\
\hline bn & 120 & 347 & 843 & 723 & 607.0897 & 701.6177 \\
\hline an & 120 & 347 & 843 & 723 & 607.0958 & 701.6453 \\
\hline wiqd & 9.895412 & 23.94417 & 69.52753 & 59.63212 & 72.49693 & 156.1541 \\
\hline iqd & 10.35321 & 24.97778 & 71.50085 & 61.14764 & 72.69948 & 150.7166 \\
\hline iqdmed & 4 & 8.75 & 22 & 18 & 29.72715 & 100.2532 \\
\hline iqdmin & 1 & 1 & 1 & 0 & 2.4651 & 39.87992 \\
\hline backward & 0.1600037 & 0.1999969 & 0.2399979 & 0.0799942 & 0.1913558 & 0.0597493 \\
\hline
\end{tabular}


Table 6: Descriptive statistics - daily

\begin{abstract}
[ts=trade size; $\mathrm{n}=$ total number of trade ticks; $\mathrm{TV}=$ trading volume; vol=statistical volatility; $\mathrm{gkr}=\mathrm{Garman}-\mathrm{Klass}$ range;
$\mathrm{APR}=$ ask pressure; $\mathrm{BPR}=$ bid pressure; INT=ordern intensity; bn=number of ticks for bid orders; an=number of ticks for ask orders; wiqd=weighted interquote duration; iqd=interquote duration; iqdmed=median interquote duration; iqdmin=minimum interquote duration; backward=backwardation. In Book 1 the statistics are computed on NT=106,820 (total number of observations), $\mathrm{N}=267$ (total number of stocks), $\mathrm{T}=400$ (average number of time periods); in the statistical volatility indicato case the total number of observations fall to 76861 (about 287 average number of time periods) because lags are used in the computation.]
\end{abstract}

\begin{tabular}{|c|c|c|c|c|c|c|}
\hline \multicolumn{7}{|c|}{ Book1 } \\
\hline & 1st Q & Median & 3rd Q & IQR & Mean & SD \\
\hline ts & 609.2031 & 1306.758 & 3367.125 & 2757.922 & 3624.847 & 7319.812 \\
\hline $\mathrm{n}$ & 44 & 131 & 397 & 353 & 358.9128 & 581.5413 \\
\hline $\mathrm{TV}$ & 36166 & 188835 & 974753 & 938587 & 2314259 & 9301036 \\
\hline vol & 0.0019659 & 0.0030109 & 0.0046434 & 0.0026775 & 0.0038384 & 0.0099262 \\
\hline gkr & $7.96 \mathrm{E}-06$ & 0.0000238 & 0.0000662 & 0.0000583 & 0.0001176 & 0.0005531 \\
\hline APR & 524.65 & 1148.131 & 3238.299 & 2713.649 & 4366.205 & 13074.88 \\
\hline BPR & 511.5686 & 1122.988 & 3185.421 & 2673.853 & 4257.039 & 12224.21 \\
\hline INT & 316.5 & 849 & 1982 & 1665.5 & 1550.955 & 1866.338 \\
\hline bn & 318 & 846 & 1980 & 1662 & 1551.161 & 1866.044 \\
\hline an & 317 & 850 & 1984 & 1667 & 1550.75 & 1866.678 \\
\hline wiqd & 12.49434 & 28.35387 & 77.72148 & 65.22714 & 73.85363 & 137.4825 \\
\hline iqd & 13.00144 & 29.47513 & 77.98251 & 64.98106 & 74.51243 & 138.701 \\
\hline iqdmed & 4 & 8 & 20 & 16 & 22.45576 & 54.38333 \\
\hline iqdmin & 1 & 1 & 1 & 0 & 1.031068 & 0.4285452 \\
\hline \multirow[t]{3}{*}{ backward } & -0.1000061 & -0.0899963 & -0.0500031 & 0.0500031 & -0.0774627 & 0.0318625 \\
\hline & & & Book2 & & & \\
\hline & 1st Q & Median & 3rd Q & IQR & Mean & SD \\
\hline ts & 583.5606 & 1286.733 & 3348.64 & 2765.079 & 3554.39 & 7552.663 \\
\hline $\mathrm{n}$ & 38 & 116.5 & 370 & 332 & 319.1074 & 469.1148 \\
\hline TV & 32306 & 159375.5 & 826573 & 794267 & 1875229 & 7117618 \\
\hline vol & 0.0020791 & 0.0031968 & 0.0050814 & 0.0030022 & 0.0039956 & 0.0028867 \\
\hline gkr & $7.30 \mathrm{E}-06$ & 0.0000257 & 0.0000766 & 0.0000693 & 0.0001108 & 0.0003499 \\
\hline APR & 492.1584 & 1058.741 & 2922.657 & 2430.499 & 3993.222 & 12409.65 \\
\hline BPR & 470.6563 & 1053.101 & 2876.246 & 2405.589 & 3994.739 & 11564.74 \\
\hline INT & 268 & 790.5 & 2073 & 1805 & 1534.219 & 1789.378 \\
\hline bn & 270 & 792 & 2073 & 1803 & 1534.504 & 1788.756 \\
\hline an & 267 & 791 & 2073 & 1806 & 1533.933 & 1790.078 \\
\hline wiqd & 12.11436 & 31.03867 & 91.6099 & 79.49555 & 82.98744 & 146.0183 \\
\hline iqd & 12.57283 & 31.63609 & 92.10583 & 79.533 & 84.81924 & 155.1365 \\
\hline iqdmed & 4 & 9 & 24 & 20 & 26.17399 & 68.38353 \\
\hline iqdmin & 1 & 1 & 1 & 0 & 1.228042 & 13.28814 \\
\hline \multirow[t]{3}{*}{ backward } & -0.1299973 & -0.1200027 & -0.0800018 & 0.0499954 & -0.1019669 & 0.0286851 \\
\hline & & & Book3 & & & \\
\hline & 1st Q & Median & 3rd Q & IQR & Mean & $\mathrm{SD}$ \\
\hline ts & 585.8146 & 1227.601 & 2970.475 & 2384.661 & 3207.283 & 7146.016 \\
\hline $\mathrm{n}$ & 30 & 101 & 351 & 321 & 302.658 & 457.7739 \\
\hline $\mathrm{TV}$ & 24624.5 & 138369 & 708838.5 & 684214 & 1710966 & 7220700 \\
\hline vol & 0.002332 & 0.0035963 & 0.0056955 & 0.0033634 & 0.0045473 & 0.0036892 \\
\hline gkr & 7.97E-06 & 0.0000304 & 0.0000923 & 0.0000843 & 0.0001738 & 0.0008069 \\
\hline APR & 499.9324 & 1073.744 & 2790.612 & 2290.68 & 4300.782 & 19656.62 \\
\hline BPR & 474.1987 & 1038.112 & 2692.889 & 2218.691 & 4100.706 & 14277.23 \\
\hline INT & 228 & 708.75 & 2003.75 & 1775.75 & 1453.693 & 1729.193 \\
\hline bn & 228 & 710 & 2003.5 & 1775.5 & 1453.952 & 1728.883 \\
\hline an & 227 & 708 & 2003.5 & 1776.5 & 1453.434 & 1729.545 \\
\hline wiqd & 12.21616 & 34.12286 & 107.3433 & 95.12711 & 100.768 & 190.4392 \\
\hline iqd & 12.93282 & 35.38755 & 108.837 & 95.90422 & 103.7459 & 202.8949 \\
\hline iqdmed & 4 & 10 & 26 & 22 & 30.73038 & 85.32622 \\
\hline iqdmin & 1 & 1 & 1 & 0 & 1.260147 & 8.459883 \\
\hline backward & 0.1600037 & 0.1900024 & 0.2300034 & 0.0699997 & 0.1919607 & 0.0609217 \\
\hline
\end{tabular}




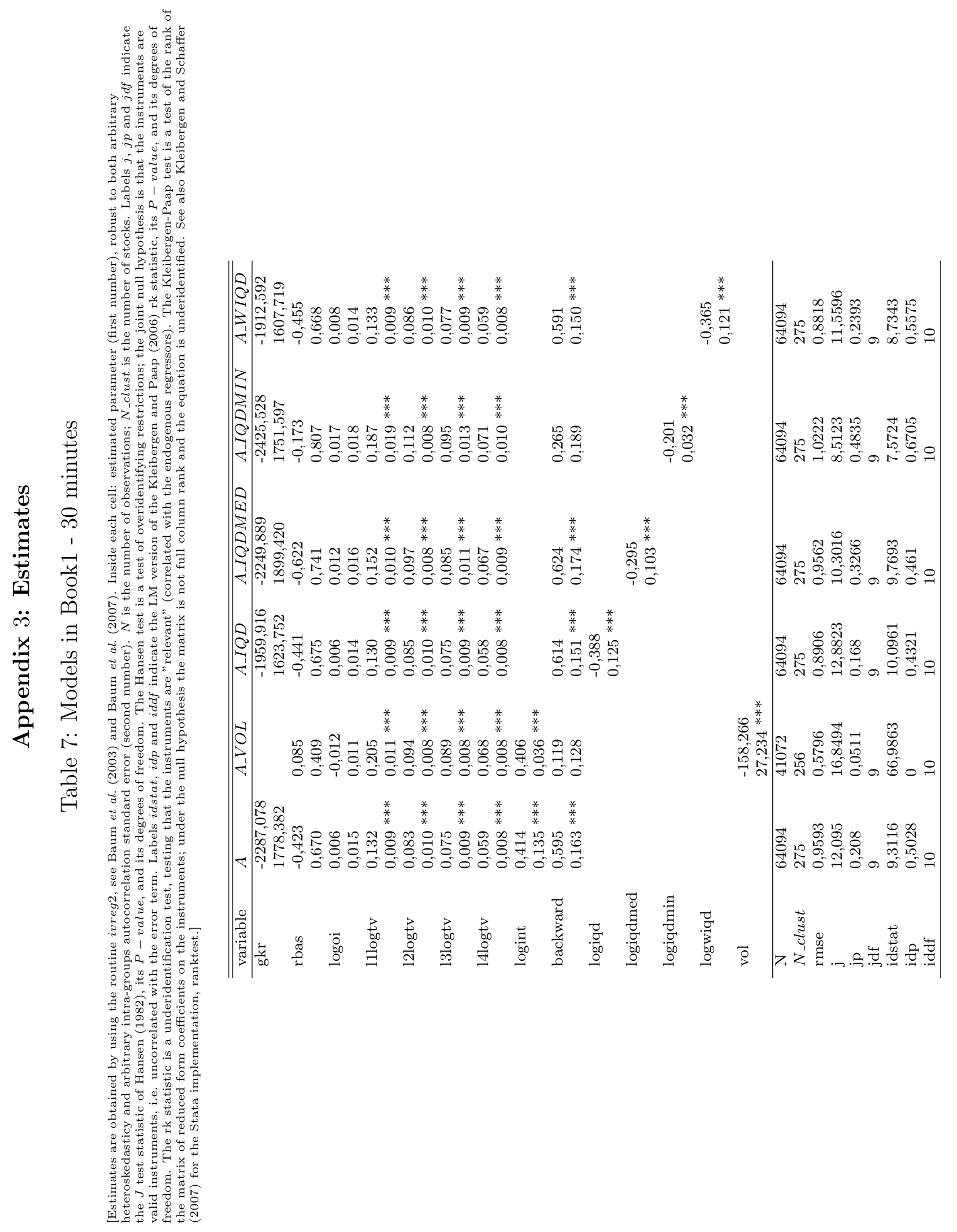




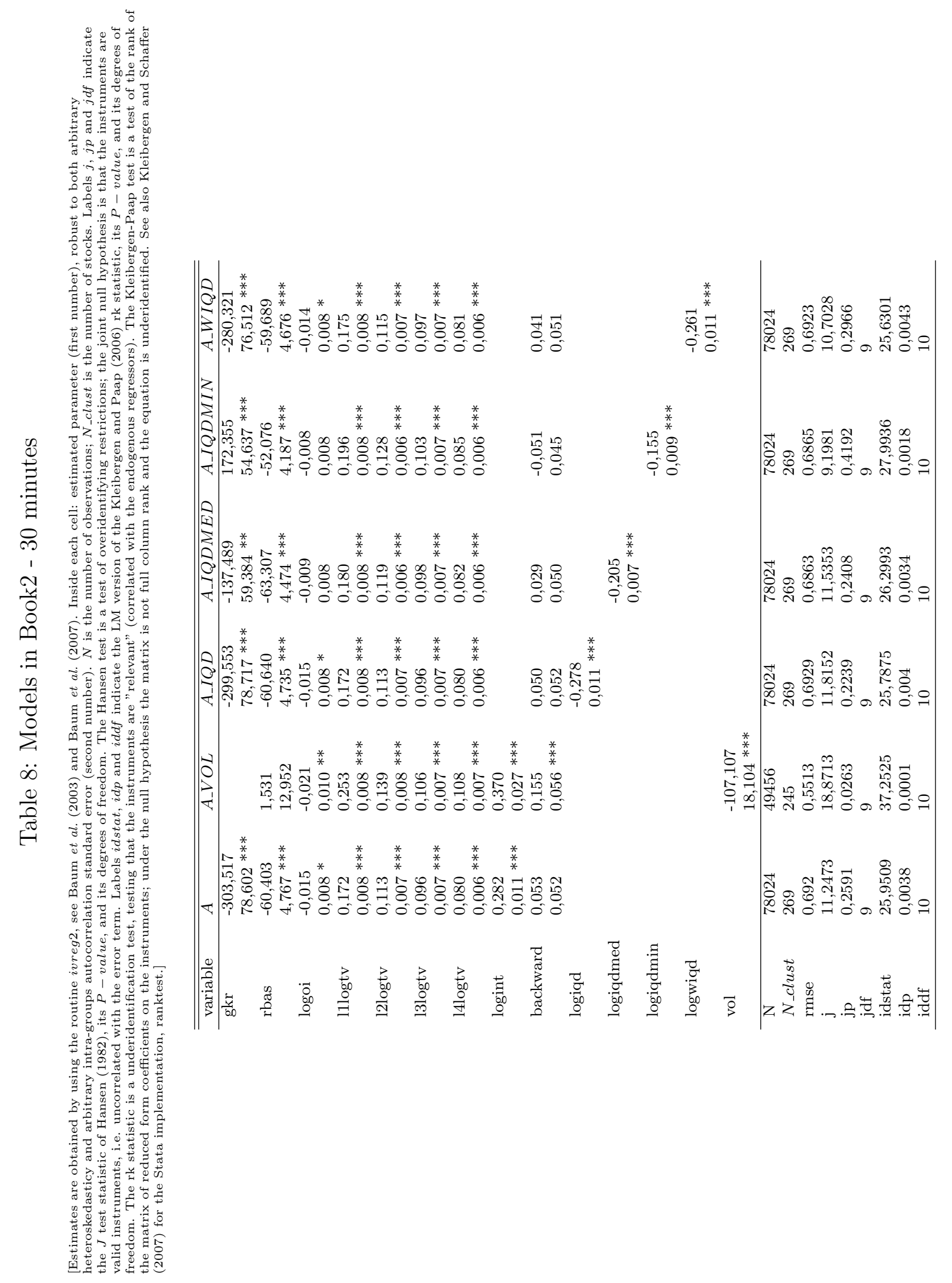




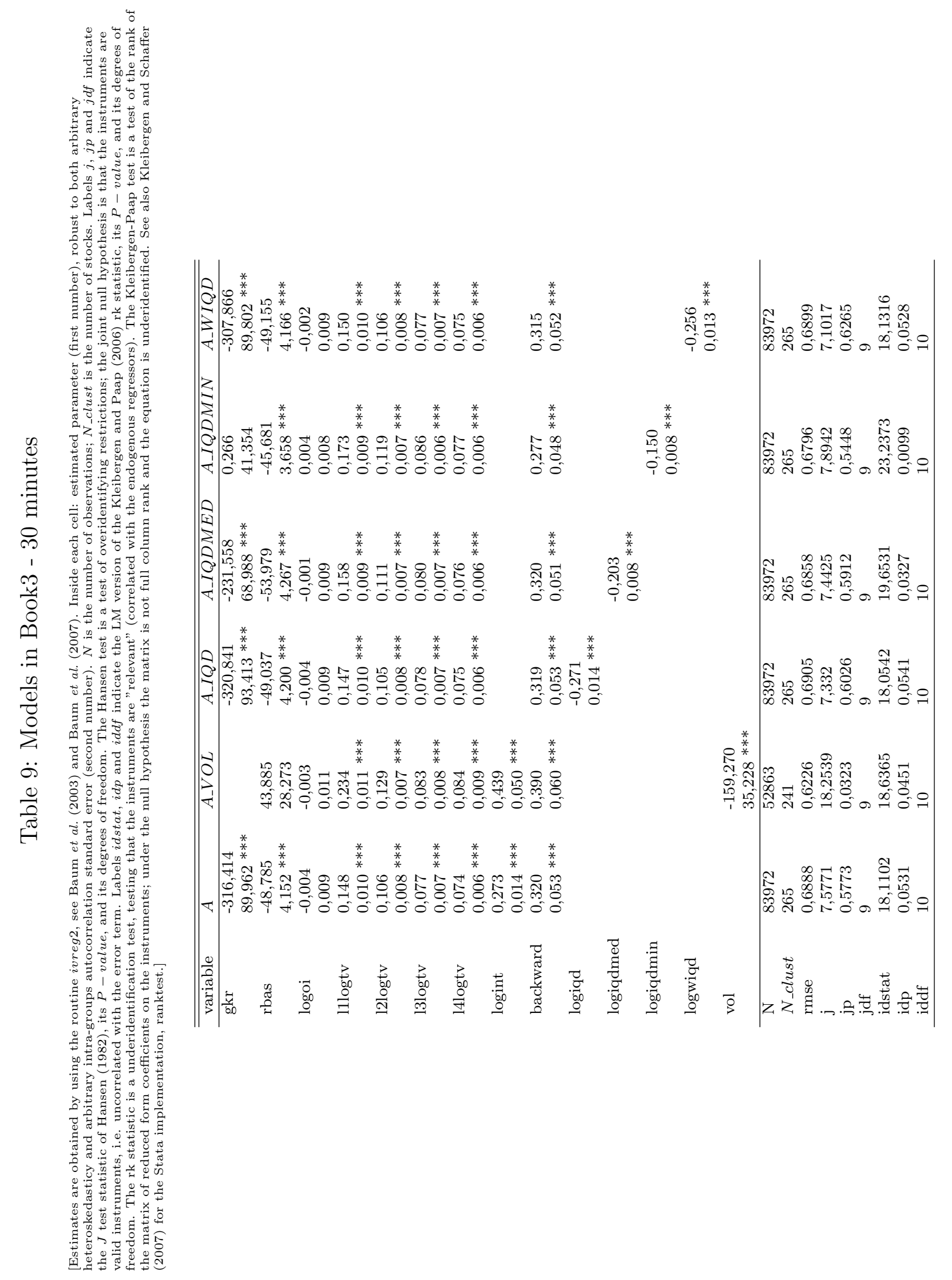




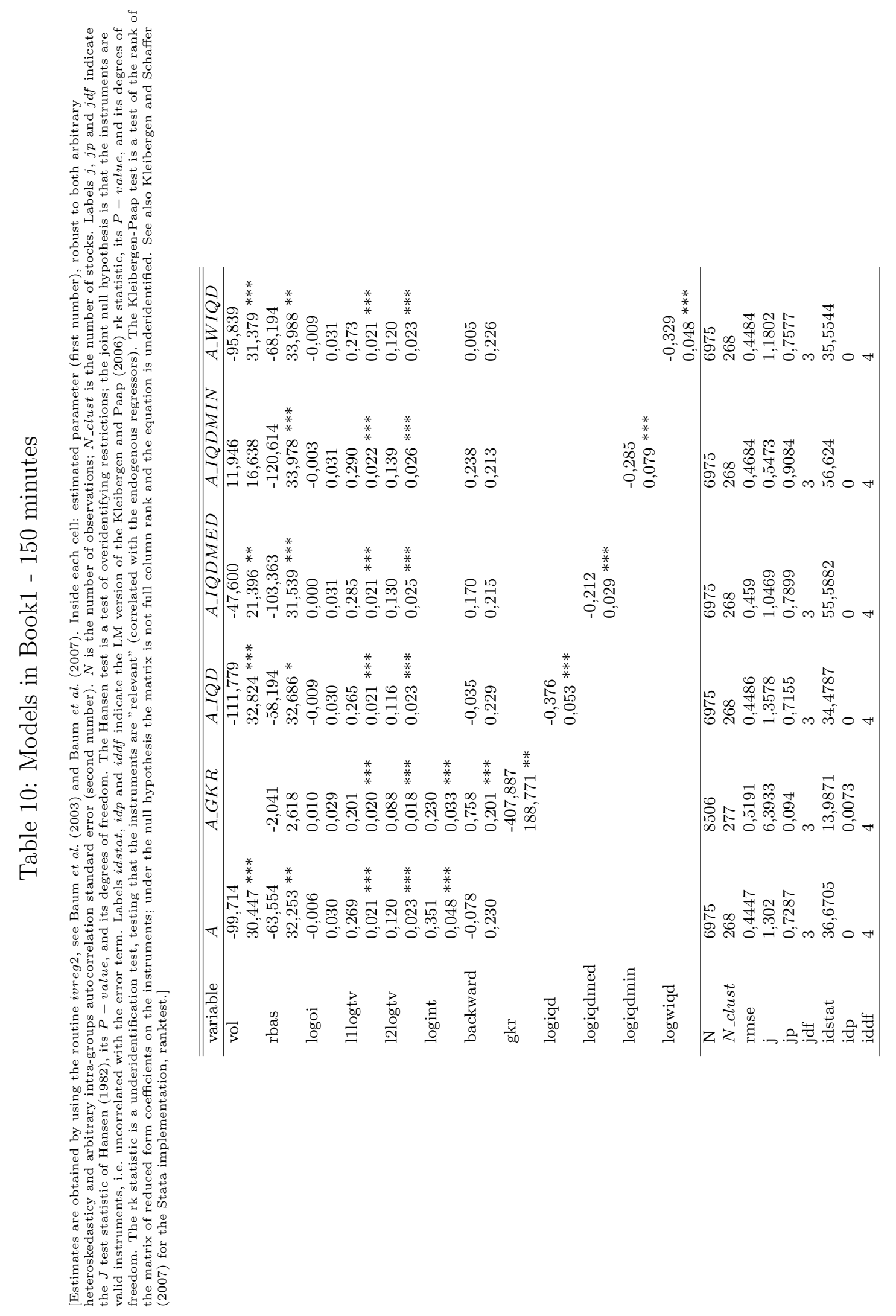




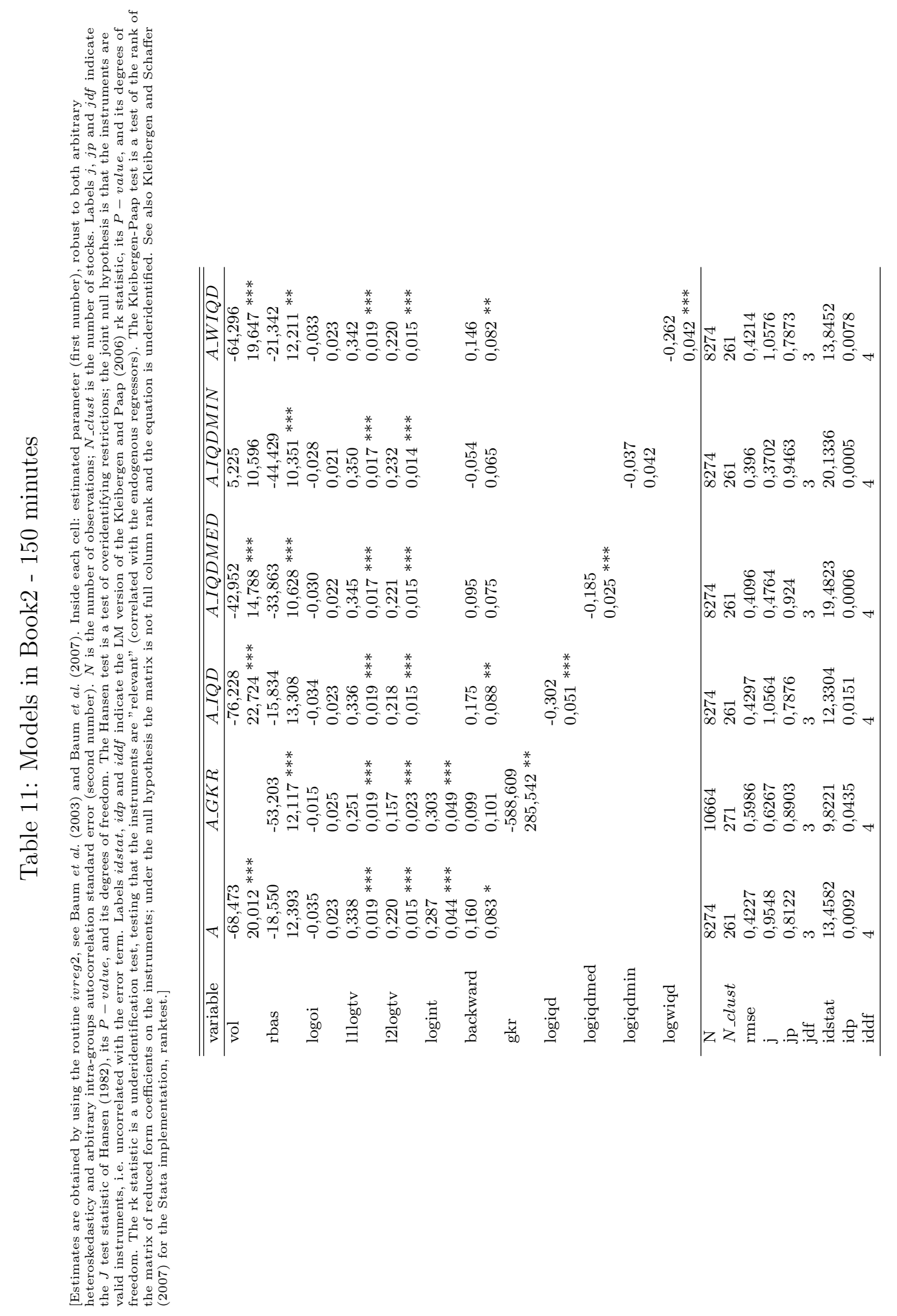




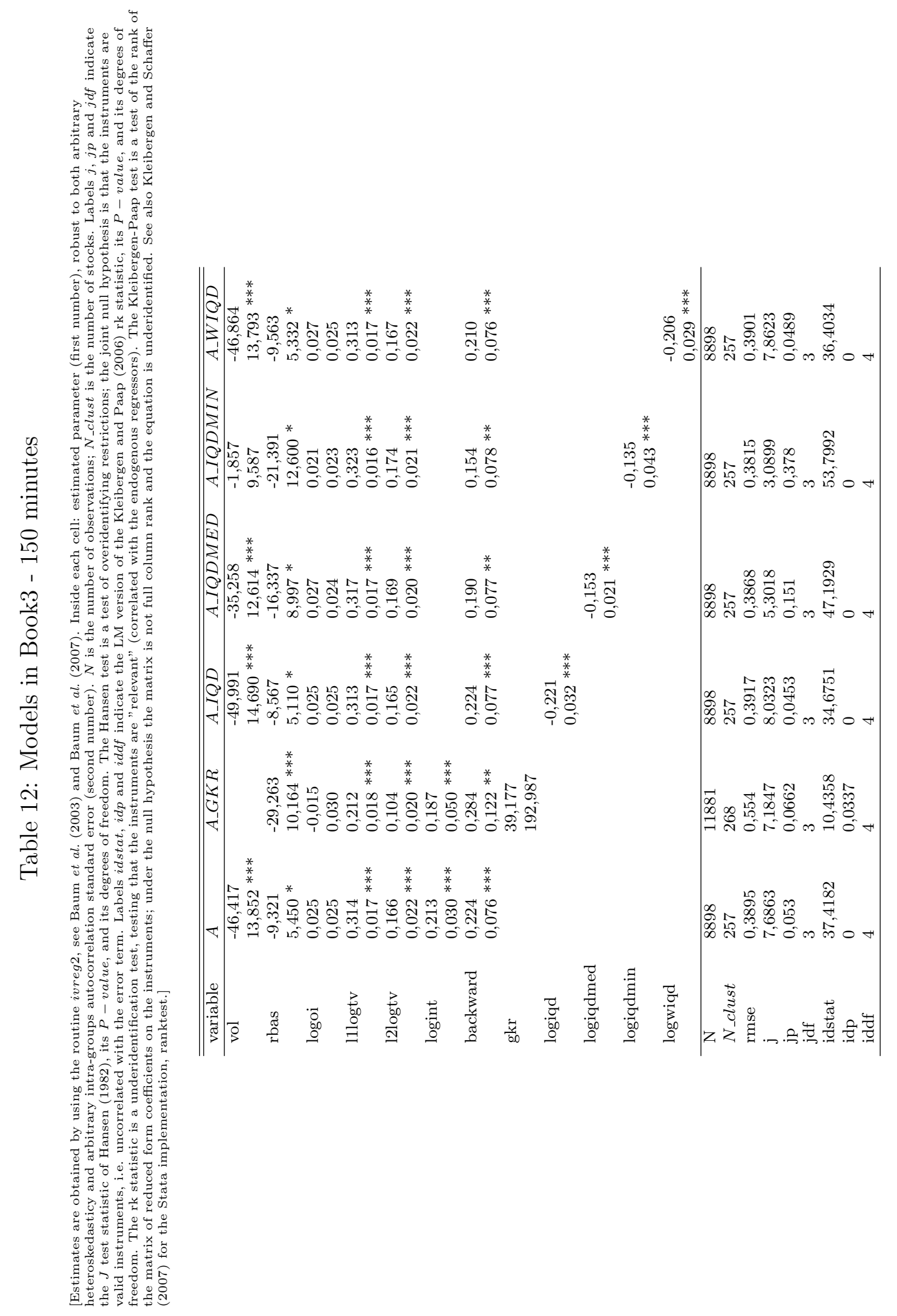




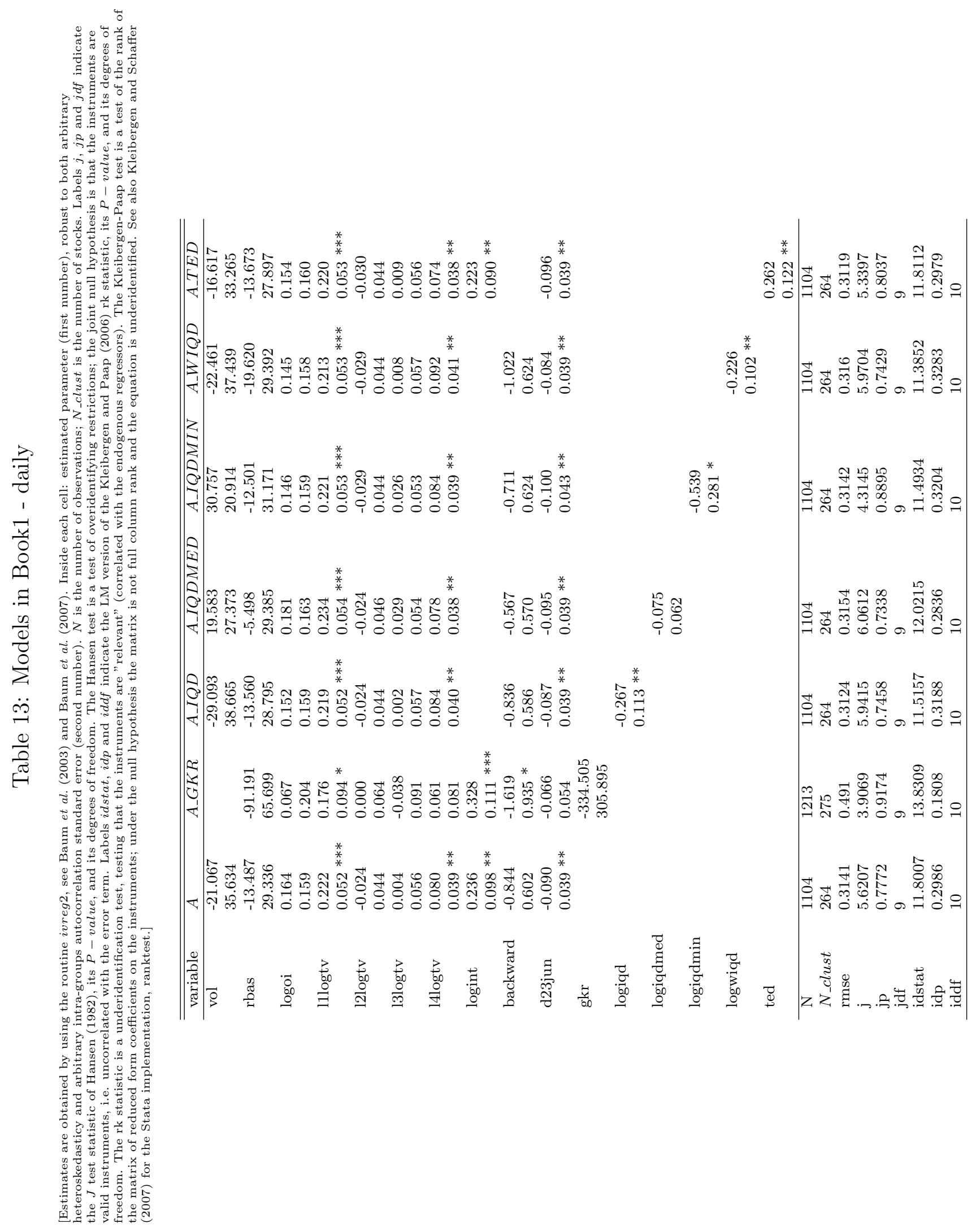




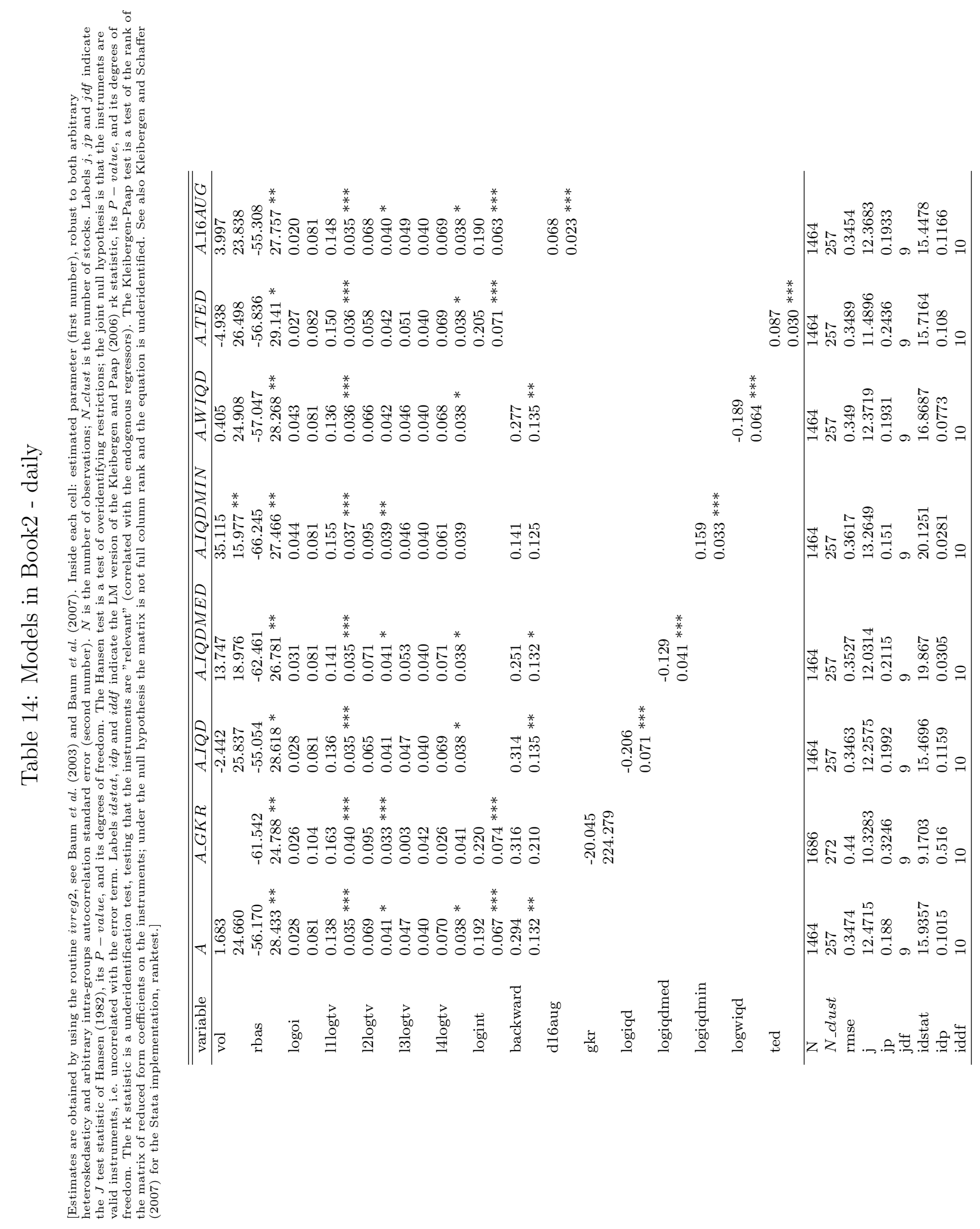




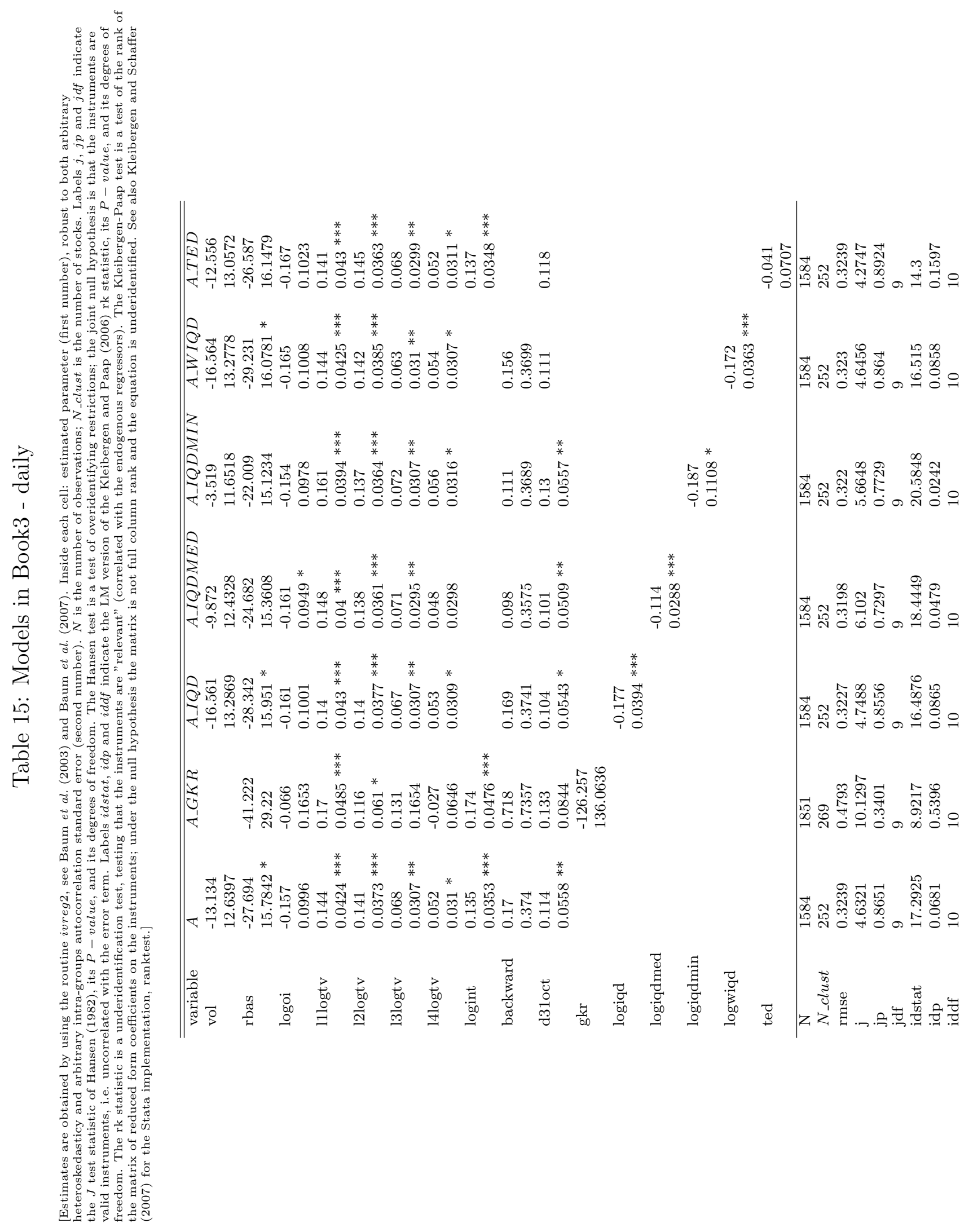

